\title{
¿DELITO MEDIOAMBIENTAL COMO DELITO DE LESIÓN?
}

\author{
JUAN LUIS FUENTES OSORIO \\ Prof. ayudante doctor (contratado doctor acreditado) \\ Área de Derecho Penal. Universidad de Jaén \\ jfuentes@ujaen.es
}

Recibido: 28 de octubre de 2010 / Aceptado: 8 de noviembre de 2010

RESUMEN: El objetivo de este artículo es plantear cómo un estudio de la relación de ofensividad en los delitos contra el medio ambiente centrado en la figura del delito de peligro es insuficiente. Aparte de olvidar tratar aspectos vinculados a la accesoriedad administrativa, corre el riesgo de no indicar el carácter individual o colectivo de la definición del medio ambiente y la influencia que cada enfoque, y la determinación del momento consumativo del bien jurídico resultante de cada uno de ellos, puede tener en la construcción de la estructura del injusto. Olvida, por tanto, que, en ocasiones y en función de estos elementos, podríamos estar ante formas de lesión consumada.

RESUM: L'objectiu d'aquest article és plantejar que un estudi de la relació d'ofensivitat en els delictes contra el medi ambient centrat en la figura del delicte de perill és insuficient. A part d'oblidar tractar aspectes vinculats a l'accessorietat administrativa, corre el risc de no indicar el caràcter individual o col-lectiu de la definició del medi ambient $\mathrm{i}$ la influència que cadascun d'aquests enfocaments, i la determinació del moment consumatiu del bé jurídic resultant de cadascun, pot tenir en la construcció de l'estructura de l'injust. Oblida, per tant, que, en ocasions i en funció d'aquests elements, podríem estar davant de formes de lesió consumada.

ABSTRACT: The aim of this article is to propose that studies of the relationship of offensivity in environmental crimes that focus on the concept of risk offences are 
insufficient. Besides not dealing with issues of administrative accessoriness, they run the risk of not indicating the individual or collective nature of the definition of the environment and the effect that each of these approaches (and the determination of the legally protected interest resulting from each of them) can have on constructing the structure of the prohibited behaviour. They do not take into account, then, that on occasions we may be dealing with actual offences.

PALABRAS CLAVE: delitos contra el medio ambiente - accesoriedad administrativa — delito de peligro — bien jurídico medio ambiente

PARAULES CLAU: delictes contra el medi ambient — accessorietat administrativa delicte de perill — medi ambient com a bé jurídic.

KEYWORDS: environmental crimes — administrative accessoriness — risk offences — environment as a legally-protected interest

Sumario: I. Introducción. II. Relación de accesoriedad administrativa. III. Bien jurídico: perspectiva y objeto. 1. Definición del bien jurídico medio ambiente. 1.1. Perspectiva antropocéntrica. 1.2. Perspectiva ecocéntrica. 1.3. Perspectiva antropocéntrica moderada. 1.4. Perspectiva ecocéntrica moderada. 1.5. Perspectiva administrativa: modelo de gestión medioambiental. 2. Elementos que incluye el medio ambiente como bien jurídico autónomo. IV. Estructura típica y del injusto. 1. Perspectiva antropocéntrica I radical. 2. Perspectiva antropocéntrica moderada. 3. Perspectivas ecocéntrica radical y moderada. V. Conclusiones. VI. Bibliografía

\section{INTRODUCCIÓN}

Una de las principales discusiones doctrinales que ha surgido en torno a los delitos medioambientales ha sido precisar qué clase de delito eran en función de su relación de ofensividad con el bien jurídico medio ambiente. Generalmente, se ha resuelto aceptando, en un primer momento, que no eran delitos de lesión sino de peligro y, posteriormente, que había que elegir uno de los dos conceptos de peligro opuestos. En el delito ecológico, por ejemplo, primero tuvo éxito el concepto de peligro concreto. Este planteamiento sostiene, explicado de modo breve, la necesidad de que la conducta 
contaminadora cree una situación efectiva de peligro para el medio ambiente normalmente se plasma en la exigencia de que se constate una destrucción de flora y fauna-. A este enfoque le ha seguido otro, actualmente predominante, conocido como peligro abstracto, que requiere que el comportamiento realizado coincida con la conducta típica o que, adicionalmente, muestre capacidad o idoneidad para lesionar el medio ambiente.

Desde mi punto de vista, reducir el problema a la necesidad de escoger una de estas posibilidades resulta insatisfactorio. Para poder iniciar una discusión sobre la relación de ofensividad en el contexto medioambiental se deben resolver previamente dos cuestiones.

La primera sería precisar la conexión existente entre el ilícito penal y el ilícito administrativo y la forma en que se va a establecer una separación entre sus ámbitos. La segunda, definir con claridad el bien jurídico medio ambiente. Su indeterminación inicial nos conduce a trabajar con una estructura del injusto que no es unívoca: ¿hablamos de delito de peligro respecto a un bien jurídico individual o colectivo? Y si es colectivo, ¿cómo se ha definido normativamente su momento consumativo? Y si es colectivo y la consumación se alcanza normativamente, por ejemplo, con una simple afectación del ecosistema, ¿podría suceder entonces que la conducta típica fuera una forma de lesión consumada y no un delito de peligro?

Asimismo, esta indeterminación dificulta discernir la conexión existente entre el medio ambiente y los bienes jurídicos individuales que, a menudo, están presentes en la descripción típica. Podrían plantearse cuestiones como las siguientes: ¿la lesión del bien individual es un elemento necesario en la estructura del injusto? O, por el contrario, ¿es un elemento accesorio que agrava la pena del delito contra el medio ambiente?

En suma, renunciar a la lesión, optar por el peligro y elegir entre las variables concreto o abstracto en el examen de la relación de ofensividad en los delitos medioambientales implica toda una serie de decisiones que no siempre se plantean en esta discusión. Una explicación estructurada de esta problemática requiere efectuar un análisis en tres fases consecutivas: 
(i) Relación de accesoriedad administrativa (grado de interdependencia: accesoriedad absoluta o relativa).

(ii) Definición del bien jurídico medio ambiente (ecocéntrico o antropocéntrico; extensión).

(iii) Determinación del injusto y la estructura típica (momento consumativo; tipo de lesión o de peligro; de peligro concreto o abstracto).

En este artículo abordaré de forma breve el primer punto y me concentraré especialmente en el segundo y el tercero. No obstante, en este último me voy a extender hasta el momento en que, una vez expuestas las opciones de la estructura del injusto que se derivan de la concepción del bien jurídico defendida y del momento consumativo elegido, habría que analizar el delito ecológico español (arts. 325 y s. CP) desde la perspectiva de la lesión, del peligro concreto o abstracto. En esta discusión tomo partido por considerar que estamos, a la vista de la redacción actual, ante un delito de peligro hipotético (art. $325 \mathrm{CP}$ ) y de lesión (art. $326 \mathrm{CP}$ ). Ello, empero, será objeto de otro artículo.

\section{RELACIÓN DE ACCESORIEDAD ADMINISTRATIVA}

La actuación penal medioambiental es accesoria respecto a la administrativa por dos razones: se subordina a ella (el ordenamiento administrativo pasa a determinar algún elemento normativo del tipo o el ámbito de lo permitido) y la secunda (complementa la actuación administrativa dentro del proceso de tutela de un determinado bien jurídico: asumiendo todo el papel sancionador - modelo absoluto- o, lo que es más correcto, actuando como cierre del sistema sancionador — modelo relativo- $)^{1}$.

\footnotetext{
1 Vid. DE LA MATA BARRANCO, N., Protección Penal del Ambiente y Accesoriedad Administrativa, Barcelona, 1996, p. 67; BLOY, R., "Umweltstrafrecht: Geschichte - Dogmatik - Zukunftsperspektiven", en $J u S, 1997$, p. 584.
} 
Ahora bien, con esta afirmación estoy respondiendo anticipadamente a varias cuestiones que hay que presentar gradualmente. En este primer nivel de análisis hay que detenerse a examinar dos aspectos.

(1) ¿La estructura del injusto del delito ecológico se asocia necesariamente con el derecho administrativo? La respuesta negativa (persecución penal autónoma) se construye indicando que el tipo medioambiental no debe incluir ninguna remisión al derecho administrativo para completar algún elemento normativo de su supuesto de hecho. La persecución penal autónoma se opone, por tanto, a la técnica de la ley penal en blanco. Y ello con el objetivo de evitar que cuestiones formales de derecho administrativo interfieran en la actividad penal ${ }^{2}$. Nos obsesiona que un acto administrativo formalmente válido, que goza de eficacia, pero que es materialmente ilícito (no respeta los márgenes de lo permitido por el ordenamiento administrativo), paralice la aplicación de un tipo penal.

Si se acepta esta autonomía textual del tipo penal, la discusión, a los efectos de la relación de ofensividad, se tendrá presuntamente por terminada, ya que parece que, si el ilícito penal no se vincula expresamente al ilícito administrativo, no habrá que estudiar necesariamente el enlace entre ambos.

El legislador español ha sostenido esta autonomía textual en los artículos 328 (1 y 3), 330, 332, 352, 353, 354, 356, 357 CP. En el resto sí se exige una conexión de forma expresa (como remisión a toda la normativa medioambiental o limitada a un acto administrativo — vid. por ejemplo el artículo $336 \mathrm{CP}^{3}-$ ). En lo que atañe al delito ecológico (arts. 325 y s. CP), se ha adoptado un sistema de accesoriedad administrativa expresa y dinámica ${ }^{4}$ : el artículo $325 \mathrm{CP}$, cuando requiere una infracción de leyes o disposiciones de carácter general protectoras del medio ambiente, (i) efectúa una remisión genérica a toda la normativa administrativa que tenga carácter medioambiental; (ii) está demandando como condición

\footnotetext{
${ }^{2}$ No es esta la única preocupación: también se discute sobre la posible ruptura del principio de legalidad, especialmente en su aspecto formal, que ello representa.

3 Tradicionalmente se denomina a estas dos formas de accesoriedad como de derecho y de acto, respectivamente.

${ }^{4}$ La remisión puede ser estática (cuando el tipo penal indique una concreta disposición administrativa) o dinámica (genérica a toda la normativa administrativa, si bien se pueden realizar ciertas concreciones precisando el ámbito sectorial, por ejemplo, cuando hay una remisión genérica a la normativa medioambiental).
} 
necesaria de la tipicidad que la conducta enjuiciada haya vulnerado la normativa administrativa medioambiental aplicable al supuesto.

Sin embargo, la autonomía textual, como ausencia de remisión expresa, no implica autonomía real. El derecho penal no se puede desvincular en ningún caso del derecho administrativo en la definición del riesgo permitido. Es en esta normativa donde se fijan los márgenes de uso racional de los recursos (relación entre libertad económica y conservación del medio ambiente) y los límites tolerados de desarrollo de acciones sitas en ámbitos de riesgo (los niveles de riesgo permitido en el contexto de la contaminación) ${ }^{5}$. El sujeto que actúa dentro de esos márgenes no puede tener responsabilidad administrativa y, lógicamente, tampoco penal ${ }^{6}$. De este modo, el respeto de la normativa administrativa por el sujeto que actúa tendrá efectos penales, incluso si estos no estuvieran expresamente previstos por un tipo penal. Ahora bien, mientras que en la remisión expresa la conducta del sujeto que no vulnera la normativa administrativa es atípica, en la tácita se traslada el problema a la antijuricidad: sería posible la justificación por la vía del ejercicio legítimo de un derecho. E incluso se podría plantear que es un comportamiento objetivamente no imputable: la conducta que respeta los límites de contaminación administrativamente fijados se sitúa dentro de los márgenes

5 Vid. DE LA MATA BARRANCO, Protección penal... cit., p. 67; ídem, "Delitos contra el medio ambiente: accesoriedad administrativa", en Estudios de Derecho judicial, n. ${ }^{\circ} 75,2005$, pp. 22 y s.; MORALES PRATS, F., "La estructura del delito de contaminación ambiental. Dos cuestiones básicas: la ley penal en blanco y el delito de peligro", en Valle Muñiz (coord.): La protección jurídica del medio ambiente, Pamplona, 1997, p. 227; ídem, "Delito de contaminación ambiental: análisis del art. 325.1. La relación entre Derecho penal y Derecho administrativo ambiental", en Quintero Olivares; Morales Prats (coord.): Estudios de Derecho ambiental: libro homenaje al profesor Josep Miquel Prats Canut, Valencia, 2008, p. 1053; SILVA SÁNCHEZ, J. M., “¿Protección penal del medio ambiente? Texto y contexto del artículo 325 del Código penal”, en La Ley, D-132, 1997, p. 1718; GARCÍA RIVAS, N., Delito ecológico. Estructura y aplicación judicial, Barcelona, 1998, p. 132; DE LA CUESTA AGUADO, P. M., Causalidad de los delitos contra el medio ambiente, 2. ${ }^{a}$ edición, Valencia, 1999, pp. 182 y ss.; PRATS CANUT, J.; MARQUĖS I BANQUÉ, M.; MORÁN MORA, C., Derecho Penal Ambiental y Derecho Comunitario. La directiva IP, Elcano, 2002, p. 89; ALASTUEY DOBÓN, C. El delito de contaminación ambiental, Granada, 2004, p. 45; MENDOZA BUERGO, B., "El delito ecológico: configuración típica, estructuras y modelos de tipificación", en Barreiro (dir.): Estudios sobre la protección penal del medio ambiente en el ordenamiento jurídico español, 2005, p. 122; BARREIRO, A.J., "El bien jurídico protegido en los delitos contra el medio ambiente en el CP de 1995", en Barreiro (dir.): Estudios sobre la protección penal del medio ambiente en el ordenamiento jurídico español, 2005, pp. 32 y s.; LASCURAIN SÁNCHEZ, J. A., "Elogio del artículo 325 del Código Penal", en Barreiro (dir.): Estudios sobre la protección penal del medio ambiente en el ordenamiento jurídico español, Granada, 2005, p. 269, 274; PAREDES CASTAÑÓN, J. M., "La accesoriedad administrativa de la tipicidad penal como técnica legislativa: efectos políticos y efectos materiales", en Gonzalo Quintero Olivares; Fermín Morales Prats (coord.): Estudios de Derecho ambiental: libro homenaje al profesor Josep Miquel Prats Canut, Madrid, 2008, p. 678; FARALDO CABANA, P., "El delito de establecimiento de depósitos o vertederos de residuos peligrosos, con especial referencia al proyecto de reforma de 13 de noviembre de 2009", en Revista Catalana de Dret Ambiental, vol. I - núm. 1, 2010, p. 20.

6 Vid. FRISCH, W., Verwaltungsakzessorietät und Tatbestandsverständnis im Umweltstrafrecht, Heidelberg, 1993, p. 8. 
del riesgo permitido, por ello no infringe objetivamente la norma prohibitiva ${ }^{7}$. La autonomía textual nos obliga a resolver por una vía diferente de la teoría del delito, pero no consigue una autonomía auténtica.

En suma, como los márgenes de riesgo permitido en el medio ambiente vienen establecidos por la normativa administrativa, no puede existir autonomía entre derecho administrativo y penal en el plano material. No obstante, sí que puede haber una autonomía formal: cuando el derecho penal decida resolver los supuestos en los que hay validez administrativamente formal pero no material de un acto administrativo conflictos de nulidad y anulabilidad- por sus propias reglas: las exigencias del principio de confianza en la licitud de las decisiones tomadas por la Administración se traslada al derecho penal mediante las figuras del error de tipo o de prohibición. En caso contrario, el derecho penal debería asumir la normativa administrativa para la resolución de dichas situaciones. Si se adopta esa solución, entonces sí acontece que cuestiones formales administrativas puedan paralizar la actuación penal.

(2) Existe, por consiguiente, una relación de accesoriedad material (venga reconocida de forma expresa o tácita) entre el derecho penal y el administrativo. La discusión, a partir de esta afirmación, se concentra en cómo conseguir que los dos órdenes no se superpongan ${ }^{8}$. Responder a esta pregunta implica escoger un criterio para distinguir el ilícito administrativo del penal. Se pueden utilizar dos modelos: el absoluto mantiene una identidad entre ambos; el relativo, en cambio, demanda que el ilícito penal presente un plus de desvalor respecto al administrativo9.

\footnotetext{
7 Vid. respecto al artículo 328 CP MUÑOZ LORENTE, J., "Diferencias y analogías entre los artículos 325 y 328 del Código Penal. El alcance del controvertido artículo 328 del Código Penal", en Revista interdisciplinar de gestión ambiental, n. ${ }^{\circ}$ 49, 2003, p. 66.

${ }^{8}$ Obviamente habría otra cuestión: qué hacer si hay una concurrencia de procesos y sanciones de los dos órdenes. Esto se solventa mediante la aplicación del principio del non bis in idem sobre supuestos que poseen una igualdad en el sujeto, hecho y fundamento.

9 Vid. GONZÁleZ GUITIÁN, L., "Sobre la accesoriedad del Derecho Penal en la protección del ambiente", en Estudios penales y criminológicos, n. ${ }^{\circ}$ 14, 1989-1990, pp. 120 y ss.; HEINE, G., "Accesoriedad administrativa en el Derecho penal del medio ambiente", en Anuario de Derecho penal y ciencias penales, tomo 46, 1993, pp. 293 y ss.; TERRADILLOS BASOCO, J., "Protección penal del medio ambiente en el nuevo Código Penal español: luces y sombras", en Estudios penales y criminológicos, n. ${ }^{\circ} 19,1996$, pp. 312 y ss.
} 
(2.1) El primer sistema, el de la accesoriedad administrativa absoluta o extrema, defiende que el derecho penal responde frente a la simple infracción administrativa. Esto sucede en dos supuestos:

(a) Cuando el derecho penal se activa para sancionar cualquier incumplimiento de la normativa administrativa. Es el modelo propio de aquellos sistemas jurídicos en los que no existen mecanismos de sanción administrativa.

(b) Cuando, en sistemas en el que hay sanciones administrativas, el derecho penal se utiliza como refuerzo del derecho administrativo sancionador. Por ejemplo, en los casos de reincidencia, no abandono de la situación administrativamente ilícita en un plazo, etc. Es lo que se denomina dependencia de segundo grado.

La coincidencia entre ilícito administrativo y penal determina que el derecho penal asuma el papel del derecho administrativo sancionador, desplazando a este último. La accesoriedad administrativa absoluta conduce, por tanto, a la "administrativización del derecho penal".

Se dice que este fenómeno implica la relegación del bien jurídico por la idea de función (de tutela de las normas organizativas de un determinado modelo de gestión sectorial establecido y controlado por la Administración), y con ello la reducción de los requisitos materiales necesarios para que exista un merecimiento de la pena: deja de conectarse con una vulneración del interés protegido o con la capacidad ex ante para producir su lesión ${ }^{10}$. Ahora bien, desde un enfoque que considera que no hay una diferencia cualitativa entre el derecho administrativo y el derecho penal, entiendo que no se puede afirmar que la "administrativización del derecho penal" represente necesariamente una sustitución del bien jurídico medio ambiente por la protección de las facultades de regulación y control de la Administración, por la tutela de las normas

10 Vid. HASSEMER, W., "Kennzeichen und Krisen des modernen Strafrecht", en ZRP, 1992, p. 381; SEELMANN, K., "Risikostrafrecht", en KritV, 1992, p. 454; DE LA MATA BARRANCO, Protección penal... cit., pp. 73 y s.; MORALES PRATS, "La estructura del delito..." cit., p. 227; ídem, "Delito de contaminación ambiental..." cit., p. 1053; SILVA SÁNCHEZ, J. M., La expansión del derecho penal, 2." edición, Madrid, 2001, pp. 125 y ss.; BRANDÁRIZ GARCÍA, J. A., "Cuestiones derivadas de la concurrencia del derecho penal y del derecho administrativo en materia de tutela del medio ambiente", en Anuario da Facultade de Dereito da Universidade da Coruña, n. ${ }^{\circ}$ 7, 2003, p. 161; FUENTES OSORIO, J.L., "Formas de anticipación de la tutela penal", en Revista Electrónica de Ciencia Penal y Criminología, 8-8, 2006, p. 24. 
organizativas de un determinado modelo de gestión sectorial. Y es que tanto las normas penales como las administrativas sancionan conductas lesivas respecto a un mismo bien jurídico protegido.

Se pueden presentar situaciones en las que la normativa administrativa recoja la sanción de conductas muy graves en relación con el bien jurídico que podrían ser reguladas por el orden penal pero para las que, por motivos distintos a su insignificancia, se ha decidido que el orden administrativo es el mecanismo más eficaz y menos lesivo de derechos. Por otro lado, se podría afirmar que el derecho penal, aparte de la protección del bien jurídico medio ambiente, también tutela las normas organizativas de un determinado modelo de gestión medioambiental establecido y controlado por la Administración ${ }^{11}$.

Las cosas así, defiendo que la "administrativización" hace referencia a la confusión que se produce entre ambas ramas del ordenamiento en la concreta protección de un bien jurídico; confusión predicable en un doble sentido:

(i) Cuando el derecho penal prescinde del principio de ultima ratio y, en concreto, del principio de fragmentariedad. La administrativización del derecho penal se produce cuando el instrumental penal se pone en funcionamiento con una conducta típica que presenta una relación de ofensividad mínima para el bien jurídico que, precisamente por la escasa intensidad del ataque que implica, debería ser únicamente objeto de sanción administrativa.

(ii) Cuando la superposición entre ambos ordenamientos genera una preponderancia absoluta del derecho penal, que se apropia del papel del derecho administrativo sancionador. Ello acontece si la reacción penal se conecta con una conducta típica que no lesiona o no puede lesionar el bien jurídico de referencia en un grado mayor del que ya recoge la normativa administrativa aplicable, de manera que el derecho penal, al ser de aplicación preferente, se convierte en la respuesta sancionadora a la infracción administrativa. Por tanto, el problema no reside en que la conducta penalmente sancionada no tenga un desvalor material, sino en que, con independencia de su entidad,

\footnotetext{
${ }^{11}$ Vid. infra: III.1.1.5.
} 
coincide con el desvalor material ya recogido en un precepto administrativo, y, así, el derecho penal asume todo el papel sancionador. Ello también representaría una infracción del principio de legalidad, ya que la determinación del núcleo esencial del injusto no la realizaría el tipo penal, sino la normativa administrativa de remisión, lo que arrojaría serias dudas sobre su constitucionalidad.

(2.2) En el sistema de accesoriedad administrativa relativa, la activación de la intervención penal requiere un plus de injusto respecto al ilícito administrativo ${ }^{12}$. Este requisito se concreta, en el ámbito medioambiental, según el modelo conocido como doble estándar. Ahora bien, este modelo se utiliza en dos direcciones.

(a) Por un lado hace referencia, en un sentido estricto, a la existencia de dos niveles de relevancia normativa del acto de contaminación ${ }^{13}$.

(a.1) Primer nivel. Se establece normativamente cuándo la conducta contaminante podrá ser objeto de sanción administrativa. Se hace coincidir con la superación del riesgo permitido por la regulación administrativa (diferencia cualitativa o "valor de contaminación”). Por debajo de esos márgenes la conducta será tolerada a todos los efectos (riesgo permitido).

\footnotetext{
12 Vid. DE LA MATA BARRANCO, Protección penal... cit., p. 74; MUÑOZ LORENTE, J., "El cambio de criterio jurisprudencial en relación con la calificación del peligro exigido para la consumación del tipo básico de los delitos contra el medio ambiente: el artículo 325 del Código Penal y su estructura de peligro hipotético (II)", en Revista interdisciplinar de gestión ambiental, n. ${ }^{\circ}$ 55, 2003, p. 74; BRANDÁRIZ, "Cuestiones..." cit., p. 159.

Reclaman de forma expresa un plus de desvalor para distinguir ilícito administrativo del penal las SSTS 1148/2004; 81/2008; 916/2008.

${ }^{13}$ Vid. PRATS CANUT; J.; MARQUÈS I BANQUÉ, M., "De los delitos contra los recursos naturales y el medio ambiente", en Quintero Olivares (dir.): Comentarios a la Parte Especial del Derecho penal, 5. ${ }^{a}$ edición, Elcano, 2005, pp. 1187 y s.; CORCOY BIDASOLO, M., "Los delitos relativos a la ordenación del territorio y el medio ambiente: una perspectiva criminológica", en Corcoy Bidasolo / Ruidiaz García (coordinadoras): Problemas criminológicos en las sociedades complejas, 2000, Pamplona, p. 91; MENDO ESTRELLA, A., "Delito "ecológico" y norma penal en blanco: la STC de 9 de octubre, ¿una nueva orientación?", en La ley penal: revista de derecho penal, procesal y penitenciario, n. ${ }^{\circ} 46,2008$, pp. 118 y ss.; ídem, El delito ecológico del art. 325.1 del Código Penal, Valencia, 2009, p. 104.
} 
(a.2) Segundo nivel. Se fija normativamente cuándo la conducta contaminante podrá ser objeto de sanción penal. Al superar ciertos límites, que siempre tendrán que ser superiores a los previstos en el primer nivel, la conducta estará absolutamente prohibida (diferencia cuantitativa o "valor límite o intolerable").

En suma, el derecho penal será competente cuando la conducta sea administrativamente ilícita y, además, sobrepase en cierta medida los límites de dicha infracción, es decir, presente un desvalor de acción o de resultado superior al administrativo. Referencia material adicional que justifica la intervención penal: son agresiones más graves al bien jurídico de referencia que las ya sancionadas por el derecho administrativo. Se evita, por consiguiente, una superposición entre el contenido del ilícito administrativo y el penal y la infracción de los principios de fragmentariedad, subsidiariedad y legalidad que su coincidencia supone.

(b) Por otro lado, dentro del margen cuantitativo, también hay una mención a dos (sub-) niveles. Mención que contesta a la pregunta: ¿en qué consiste dicho plus? Se mantiene que $^{14}$ :

(b.1) Hay que comprobar que existe una lesión del medio ambiente.

(b.2) Basta la puesta en peligro concreto de cierta gravedad del medio ambiente.

(b.3) Simplemente se requiere que la conducta posea capacidad para producir una lesión de cierta gravedad del medio ambiente.

Me gustaría detenerme sobre tres cuestiones:

${ }^{14}$ Sobre ambos, vid. CORCOY BIDASOLO, “Los delitos...” cit., p. 92. 
(i) Insisto en que la lesión o la puesta en peligro concreta producida o la capacidad para ello, reclamada penalmente, debe ser mayor a la marcada para que la conducta pueda considerarse un ilícito administrativo. Es evidente que esto sucede cuando la relación entre el ilícito administrativo y el penal se encuentra en una escala de injusto: peligro abstracto - peligro concreto, peligro abstracto/concreto - lesión. Sin embargo, cuando en ambos ilícitos hay una referencia al mismo nivel de ofensividad dentro de esta escala (por ejemplo, ambos supuestos de hecho, administrativo y penal, se limitan a demandar cierta capacidad lesiva), se requiere la inclusión de una cláusula adicional de notoriedad: tenga capacidad lesiva para producir un resultado (más) grave (solución del ejemplo), produzca un resultado lesivo (más) grave.

En ocasiones se determina fijando, como presunción de la concurrencia de ese valor límite, el que la acción realizada haya rebasado un determinado nivel de contaminación ${ }^{15}$. Por ejemplo, se afirma que la conducta tiene capacidad lesiva grave, superior a la prevista en la infracción administrativa, siempre que sobrepase en una cantidad fija o en un porcentaje concreto (por ejemplo, un 100\%) los límites marcados en el supuesto de hecho administrativo ${ }^{16}$.

(ii) La plasmación de una de estas tres opciones (b.1-b.3) en el texto típico, acompañadas, si fuera necesario, de una cláusula adicional de notoriedad, cumple uno de los requerimientos marcados por el Tribunal Constitucional para considerar que las leyes penales en blanco son respetuosas con el principio de legalidad: la especificación del núcleo esencial del injusto de la prohibición o mandato (grado de afectación del bien jurídico protegido) en el tipo penal.

El TC ha intervenido en diversas ocasiones para precisar cuándo el uso de la técnica de la ley penal en blanco es compatible con el principio de legalidad. En concreto, la constitucionalidad de la ley penal en blanco requiere la satisfacción de cuatro requisitos: presencia de un reenvío normativo expreso a leyes y disposiciones generales; precisión de la conducta considerada delictiva (la norma

\footnotetext{
15 Vid. SAMSON, E., "Kausalitäts- und Zurechnungsprobleme im Umweltstrafrecht", en ZStW, n. ${ }^{\circ} 99$, 1987, pp. 622 y ss.

16 Un ejemplo sería el artículo $379.1 \mathrm{CP}$ : "el que condujere un vehículo de motor o un ciclomotor a velocidad superior en sesenta kilómetros por hora en vía urbana o en ochenta kilómetros por hora en vía interurbana a la permitida reglamentariamente...".
} 
penal debe contener el núcleo esencial de la prohibición); satisfacción de la exigencia de certeza; que el reenvío esté justificado por las necesidades de protección del bien jurídico tutelado ${ }^{17}$.

No se satisface este requisito cuando se puede conocer todo el injusto penal acudiendo a la normativa administrativa. Ello acontece cuando el tipo no incluye ninguna referencia al desvalor de la acción o del resultado adicional al que ya recoge la infracción administrativa, de forma que la prohibición penal en su conjunto viene determinada por la normativa administrativa, con cuyo ilícito coincide el ilícito penal ${ }^{18}$.

Por los motivos indicados los preceptos relativos al medio ambiente, aparte de la remisión a la normativa administrativa, deben añadir ciertos términos en la descripción típica que le den un contenido de injusto material propio, adicional al administrativo:

"puedan perjudicar gravemente el equilibrio de los sistemas naturales" (art. $328 \mathrm{CP}$ ), "con grave perjuicio para el medio ambiente" (art. $332 \mathrm{CP}$ ), "de modo que perjudique el equilibrio biológico" (art. $333 \mathrm{CP}$ ) ${ }^{19}$. El artículo 325 CP también es un ejemplo de ello. Cuando el tipo reclama de forma expresa la realización de actos contaminantes "que puedan perjudicar gravemente el equilibrio de los sistemas naturales", está indicando

17 Vid. SSTC 127/1990; 118/1992; 111/1993; 62/1994; 24/1996; 120/1998; 16/2004; 24/2004. Vid. GARCÍA ARÁN, M., "Remisiones normativas, leyes penales en blanco y estructura de la norma penal", en Estudios penales y criminológicos, n. ${ }^{\circ}$ 16, 1992-1993, pp. 63 y ss.; MORALES PRATS, "La estructura del delito..." cit., pp. 234 y ss.; ídem 2002, pp. 63-67; CONDE-PUMPIDO TOURON, C., "La tutela del medio ambiente. Análisis de sus novedades más relevantes", en La Ley, D-133, 1996, pp. 1551 y s.; TERRADILLOS BASOCO, J., "Delitos relativos a la protección del patrimonio histórico y del medio ambiente", en J. Terradillos Basoco (ed.): Derecho penal del medio ambiente, Madrid, 1997, p. 46; SILVA SÁNCHEZ, “¿Protección penal...” cit., pp. 1717 y s.; DE LA CUESTA ARZAMENDI, J. L., "Delitos contra los recursos naturales y el medio ambiente: Capítulo III, Título XVI, Libro II del Nuevo Código Penal de 1995", en Actualidad Penal, 1998, pp. 294 y s.; CORCOY BIDASOLO, "Los delitos..." cit., pp. 86 y s.; SANTANA VEGA, D.M., La protección penal de los bienes jurídicos colectivos, Madrid, 2000, pp. 212 y ss.; SESSANO GOENAGA, J. C., "La protección penal del medio ambiente", en Revista Electrónica de Ciencia Penal y Criminología, 04-11, 2002, pp. 8 y ss.; MUÑOZ LORENTE, "El cambio de criterio..." cit., p. 74; BARREIRO, "El bien jurídico..." cit., p. 54; MENDO ESTRELLA, El delito ecológico... cit., pp. 87 y ss.

18 Vid. STC 24/2004.

19 MORALES PRATS, “Delito de contaminación ambiental...” cit., p. 1057. En contra, respecto al artículo 325 CP, HUERTA TOCILDO, S., "Principios básicos del Derecho penal y artículo 325 del CP", en Revista Penal, n. ${ }^{\circ}$ 8, 2001, pp. 45 y ss. pues considera que "el ilícito administrativo condiciona por completo la aparición el ilícito penal aun no coincidiendo exactamente con él [...] tal infracción no actúa como límite de una tipicidad prefigurada sino que contribuye a su configuración en tanto que presupuesto condicionante de la misma" ("Principios básicos...", cit., p. 47). 
que no basta la mera infracción administrativa, requiere asimismo una posibilidad de perjuicio grave del medio ambiente ${ }^{20}$.

No obstante, y tal como he indicado, en ocasiones la infracción administrativa presupone esa posibilidad de perjuicio grave del medio ambiente (especialmente en los supuestos de infracciones muy graves). Deja, así, un espacio reducido al derecho penal: en tal caso, se tendrá que optar obligatoriamente por la exigencia de una posibilidad de perjuicio gravísimo o un desvalor del resultado superior al previsto administrativamente.

(iii) El ilícito administrativo (en su sentido material) y el penal mantienen una relación de ofensividad con el medio ambiente. Entre ambos se establece una distinción cuantitativa $^{21}$. La controversia se ha de centrar desde este momento en si ese plus será una lesión más grave o una puesta en peligro, concreta o abstracta, más grave que la prevista administrativamente. El análisis de la decisión político-criminal adoptada al respecto viene condicionado por la estructura del injusto: nos va a dar un baremo que nos permite situar de forma escalonada, en función de su relación de ofensividad, las conductas que representan un ilícito administrativo y penal. Ahora bien, en el contexto medioambiental no existe una estructura del injusto unívoca: esta va a depender de la definición del bien jurídico medio ambiente, de la determinación de su extensión y de su momento consumativo a efectos penales. Únicamente cuando hayamos precisado estos

\footnotetext{
20 Vid. DE LA MATA BARRANCO, Protección penal... cit., p. 108; ALENZA GARCÍA, J. F. "Las sanciones administrativas y penales en materia ambiental: Funciones y problemas de articulación", en Corcoy Bidasolo (dir.): Derecho penal de la empresa, Pamplona, 2002, p. 611; ALASTUEY, El delito... cit., p. 51; MENDOZA, "El delito ecológico..." cit., p. 123.

En el artículo $325 \mathrm{CP}$ se adopta de forma expresa un sistema de accesoriedad administrativa relativa. Así, por ejemplo, DE LA MATA BARRANCO, Protección penal... cit., pp. 74 y s., 239; BRANDÁRIZ, "Cuestiones..." cit., p. 158; OLMEDO CARDENETE, M.; RODRÍGUEZ FERNÁNDEZ, I., "Artículo 325 y 326", en Cobo del Rosal (dir.): Comentarios al Código penal, tomo X, vol. II, Madrid, 2006, p. 209; MENDO ESTRELLA, "Delito ecológico..." cit., p. 107; idem, El delito ecológico... cit., p. 87.

${ }^{21}$ Tal y como señala SILVA SÁNCHEZ (Delitos contra el medio ambiente, Valencia, 1999, pp. 104 y ss., p. 20 , nota 13,21$)$ la diferencia cuantitativa reside en el "grado de probabilidad de la lesión así como la magnitud de esta lesión", mientras que la cualitativa se refiere a conductas igualmente peligrosas pero que presentan diferente relevancia penal (hay una decisión valorativa de ponderación de intereses que determina si la conducta debe ser objeto de sanción penal). Otros autores defienden, en cambio, que la distinción entre derecho administrativo y penal es cualitativa porque en el ilícito administrativo solo se requiere superar los límites legales o reglamentarios y no se exige probar que posee una capacidad lesiva respecto al medio ambiente, lo que sí se pide al delito ecológico. Vid. CORCOY BIDASOLO, "Los delitos..." cit., pp. 79, 91 y s.; ídem, "Protección penal del medio ambiente: legitimidad y alcance. Competencia penal y administrativa en materia de medio ambiente", en Corcoy Bidasolo (dir.): Derecho penal de la empresa, 2002, Pamplona, p. 638; ALENZA GARCÍA, "Las sanciones administrativas..." cit., p. 611.
} 
aspectos podremos fijar si el criterio cuantitativo de distinción entre ambos ilícitos fue de lesión o de peligro (un resultado de peligro o la demanda de una mayor intensidad lesiva).

\section{BIEN JURÍDICO: PERSPECTIVA Y OBJETO}

La construcción del injusto penal del delito ecológico gira en torno a la tutela medio ambiente. Esta certeza es insuficiente. La fijación de la estructura del injusto requiere previamente definir el bien jurídico medio ambiente estableciendo su intensión y su extensión. La respuesta será distinta en función del enfoque individual o colectivo que se utilice.

\section{Definición del bien jurídico medio ambiente}

El medio ambiente, como bien jurídico penal, se puede definir tanto desde un encuadre individual como desde otro colectivo. Estas perspectivas van a recibir una denominación específica en el contexto medioambiental: antropocéntrica y ecocéntrica, respectivamente ${ }^{22}$.

\footnotetext{
22 Vid. DE LA MATA BARRANCO, Protección penal... cit., pp. 46 y ss.; SILVA SÁNCHEZ, “¿Protección penal...” cit., p. 1715; CORCOY BIDASOLO, "Los delitos...” cit., pp. 64 y ss; ídem, 2002, pp. 625 y ss.; ALCÁCER GUIRAO, R., "La protección del futuro y los daños cumulativos", en Revista Electrónica de Ciencia Penal y Criminología [en línea], n. ${ }^{\circ}$ 04-08, 2002, pp. 3 y ss.; ALASTUEY, El delito... cit., pp. 15 y ss.; BARREIRO, "El bien jurídico..." cit., pp. 39 y ss.; OLMEDO, RODRÍGUEZ, "Artículo 325..." cit., pp. 187 y ss.; REGIS PRADO, L., "El ambiente como bien jurídico penal: aspectos conceptuales y delimitadores", en Revista Penal, n. ${ }^{\circ} 22,2008$, pp. 122 y s.; MENDO ESTRELLA, El delito ecológico... cit., pp. 46 y ss. Vid. también la abundante literatura alemana RENGIER, R., "Zur Bestimmung und Bedeutung der Rechtsgüter im Umweltstrafrecht", en Neue Juristische Wochenschrift, 1990, pp. 2506 y ss.; ídem, Strafrecht. Besonderer Teil, vol. II, 10. ${ }^{a}$ edición, Múnich, 2009, marg. 47/9 y ss.; HOHMANN, O., "Von der Konsequenzen einer personalen Rechtsgutsbestimmung im Umweltstrafrecht", en GA, 1992, pp. 80 y ss.; KUHLEN, L., "Umweltstrafrecht - auf der Suche nach einer neuen Dogmatik", en $Z S t W$, n. ${ }^{\circ}$ 105, 1993, pp. 702 y ss.; S STRATENWERTH, G., “Zukunftssicherung mit den Mitteln des Strafrechts?”, en ZStW, n. ${ }^{\circ} 105,1993$, pp. 682 y ss.; KÜHL, K., "Anthropozentrische oder nichtanthropozentrische Rechtsgüter im Umweltstrafrecht?", en J. NidaRümelin, D. v. d. Pfordten (edit.): Ökologische Ethik und Rechtstheorie, Baden-Baden, 1995, pp. 251 y ss.; BLOY, "Umweltstrafrecht..." cit., pp. 578 y ss.; KINDHÄUSER, U., "Elementos fundamentales del derecho penal medioambiental alemán", en Revista de Ciencias Penales, vol. 1, n. ${ }^{\circ}$ 2, 1998, pp. 501 y ss.; VÖHRINGER, M., "Anthropozentrische oder nichtanthropozentrische Rechtsgüter im Umweltstrafrecht", en Rechtsphilosophisches Seminar im Sommersemester 1999 zum Thema "Die Bedeutung der Philosophie für strafrechtliche Grundlagenprobleme" (Universität Tübingen - Juristische Fakultät), [en línea], 1999, pp. 9 y ss.; MÜLLER-TUCKFELD, J.C., "Ensayo para la abolición del Derecho penal del medio ambiente", en La insostenible situación del Derecho penal, Granada, 2000, pp. 508 y ss.; WOHLERS, W., Deliktstypen des Präventionsstrafrechts. Zur Dogmatik "moderner" Gefährdungsdelikte, Berlín, 2000, pp. 130 y ss.
} 


\subsection{Perspectiva antropocéntrica}

El medio ambiente no existe como bien jurídico independiente, los únicos bienes protegidos son los individuales. Un ataque contra el medio ambiente se considera exclusivamente un modo de comisión de una agresión (que se suele estimar como una forma de delito de peligro) indiscriminada ${ }^{23}$ y mediata contra bienes jurídicos individuales ${ }^{24}$.

Se le critica a este planteamiento, por un lado, que niega la autonomía del medio ambiente como bien jurídico. Por otro, su conexión difusa con el bien jurídico individual tutelado. Consiguientemente requiere determinar con carácter previo cuáles son estos bienes individuales: normalmente serán la vida o la integridad física, pero también podrían ser otros como el patrimonio ${ }^{25}$.

\subsection{Perspectiva ecocéntrica}

Admite el medio ambiente como bien jurídico por el valor intrínseco que posee, con independencia del individuo, al que reclama que asuma su responsabilidad de respeto y cuidado. Esta exigencia se suele plasmar en una solicitud de reconocimiento de derechos propios a la naturaleza.

De este modo surge el medio ambiente como bien jurídico autónomo, rechazando cualquier tipo de subordinación a los bienes jurídicos individuales.

Se reprocha a este enfoque que la concesión de derechos subjetivos a la naturaleza es incompatible con el carácter antropocéntrico del ordenamiento jurídico y que otorgaría

\footnotetext{
23 En el sentido de que no se atenta contra la vida o integridad de un sujeto concreto sino de muchos, HOHMANN, "Von der Konsequenzen..." cit., p. 84.

24 Vid. HOHMANN, "Von der Konsequenzen..." cit., p. 84; BLOY, “Umweltstrafrecht...” cit. p. 581. Críticos KUHLEN, "Umweltstrafrecht..." cit., pp. 703 y s.; MÜLLER-TUCKFELD, "Ensayo...” cit., p. 520 .

${ }^{25}$ HOHMANN ("Von der Konsequenzen...” cit., p. 84) los concreta en la vida, la integridad física y la salud pública.
} 
derechos a quienes no podrían asumir las obligaciones que incluyen ${ }^{26}$. También se señala que el medio ambiente y los elementos que lo componen son objetos y no sujetos de derecho: olvida que en nuestro sistema jurídico las personas son las que consideran valiosa la naturaleza y no al revés ${ }^{27}$. Asimismo se afirma que asumir este enfoque ecocéntrico conduce a admitir la posibilidad de su tutela incluso en contra del hombre, a desconocer la relación recíproca que existe entre el individuo y el medio ambiente ${ }^{28}$ (aunque más bien habría que decir que desconoce que esa relación recíproca es de vasallaje del medio ambiente al hombre).

En este reproche se atisba una preocupación por un cambio de preeminencia en la relación medio ambiente/desarrollo económico a favor del primero (a diferencia de lo que ocurre ahora). Este giro bloquearía todas las decisiones económicas que fueran agresiones que afectaran a la situación y evolución de la naturaleza, que, lógicamente, estarían prohibidas ${ }^{29}$.

Por estos motivos la doctrina penal se suele centrar en la demanda de autonomía plena del medio ambiente, abandonando cualquier petición de concesión de derechos ${ }^{30}$.

No obstante, la crítica de mayor calado en el ámbito penal es la que insiste en su vaguedad: es un bien jurídico que no presenta contornos $\operatorname{claros}^{31}$. De aquí se deriva la conclusión de que no puede ser objeto de tutela penal ${ }^{32}$. A ello hay que responder que el medio ambiente no es un bien jurídico abstracto o espiritual. Es perfectamente visible,

\footnotetext{
26 Vid. KINDHÄUSER, “Elementos...” cit., p. 502; MÜLLER-TUCKFELD, “Ensayo...” cit., p. 509; WOHLERS, Deliktstypen... cit., p. 132; ALCÁCER, "La protección del futuro..." cit., p. 4, que insiste en la ausencia de derechos del medio ambiente e incluso de deberes en un sentido estricto por cuanto los deberes relativos al medio ambiente se construyen sobre el derecho de los ciudadanos a "condiciones tolerables de vida".
}

27 Vid. SANZ LÓPEZ, C.; SÁNCHEZ ALHAMA, J., Medio ambiente y sociedad. De la metáfora organicista a la preservación ecológica, 2. 'a edición, Granada, 1998, p. 152.

28 Vid. HOHMANN, “Von der Konsequenzen...” cit., p. 83; DE LA MATA BARRANCO, Protección penal... cit., p. 52; STEINDORF, J., Umweltstrafrecht, 2. ${ }^{a}$ edición, Berlín-Nueva York, 1997, marg. vor 324/13; WOHLERS, Deliktstypen... cit., p. 132.

29 Vid. en este sentido VÖHRINGER, “Anthropozentrische...” cit., pp. 13 y s.; WOHLERS, Deliktstypen... cit., p. 133.

${ }^{30}$ Vid. ALASTUEY, El delito... cit., p. 34.

${ }^{31}$ Vid. HOHMANN, "Von der Konsequenzen..." cit., p. 83; STRATENWERTH, "Zukunftssicherung..." cit., p. 683.

32 “[...] también se ha utilizado la falta de taxatividad o abstracción en la descripción de los bienes jurídicos colectivos como coartada para defender la impunidad de las infracciones de intereses esenciales [...]", PORTILla CONTRERAS, G., El Derecho Penal entre el cosmopolitismo universalista y el relativismo posmodernista, Valencia, 2007, p. 356. 
aprehensible (por ejemplo, vemos un ecosistema y los elementos que lo integran: un río, la vegetación y los animales que en él habitan) y lesionable ${ }^{33}$. El problema para el derecho penal se halla en que el medio ambiente no tiene límites perfectamente definidos y sufre de hipersensibilidad: es un sistema dinámico e interactivo que llega finalmente a coincidir con el planeta y se ve afectado, en mayor o menor medida, por cualquier comportamiento. La vaguedad se tiene que resolver con el establecimiento de un límite normativo en estos dos aspectos. Por tanto, los defensores de un enfoque ecocéntrico se ven necesariamente obligados a fijar la (i) extensión del ecosistema analizado, (ii) el momento consumativo de referencia ${ }^{34}$.

\subsection{Perspectiva antropocéntrica moderada}

Los defensores de esta opción ${ }^{35}$, a diferencia de su versión radical, sí reconocen la autonomía del medio ambiente. Sin embargo, establecen una conexión con los intereses individuales: el mantenimiento del equilibrio del sistema natural dentro de unos límites es una condición esencial del desarrollo de la vida humana. Por esta razón, la

\footnotetext{
33 Vid. KÜHL, "Anthropozentrische..." cit., p. 257; SOTO NAVARRO, S., "Concreción y lesión de los bienes jurídicos colectivos", en Anuario de derecho penal y ciencias penales, tomo 58, 2005, p. 910. "En realidad, la dificultad que comporta el proceso de concreción de los bienes jurídicos colectivos no estriba, a mi entender, en su naturaleza ideal, sino en la ineficacia de los criterios tradicionalmente empleados para delimitar unidades que constituyan concretas formas de manifestación del bien jurídico y sobre las que pueda estimarse su lesión" (SOTO NAVARRO, "Concreción y lesión..." cit., p. 904). Y es que en los bienes jurídicos colectivos el objeto material del delito no coincide con el individuo ni está subjetivamente vinculado con él. En suma, "con los bienes jurídicos colectivos el criterio del sujeto pasivo individual no funciona para determinar su afección", "Concreción y lesión..." cit., p. 905.
}

${ }^{34}$ Vid. infra, IV.3. Insiste en la exigencia de concreción frente a la renuncia a la protección, PORTILLA CONTRERAS, G., "Principio de intervención mínima y bienes jurídicos colectivos", en Cuadernos de Política Criminal, n. ${ }^{\circ} 39,1989$, p. 740; ídem, El derecho penal... cit., p. 356: “[...] la solución deberá pasar por la exigencia de concreción del objeto a proteger, pues no hay motivo para pensar que los valores colectivos no puedan ser descritos y, por tanto, asegurados con los instrumentos penales".

35 Vid. MORALES PRATS, F., "Técnicas de tutela penal de los intereses difusos. Intereses difusos y derecho penal", en Cuadernos de Derecho Judicial, 1994, pp. 82 y s.; ídem, "Delito de contaminación ambiental..." cit., p. 1043; DE LA CUESTA AGUADO, P. M., "Algunas consideraciones acerca de la necesidad de protección del medio ambiente como bien jurídico", en Anales de la Universidad de Cádiz, XI, 1996, pp. 273 y ss.; SILVA SÁNCHEZ, “¿Protección penal...” cit., p. 1715; ídem, Delitos... cit., pp. 98 y s.; GARCÍA RIVAS, Delito ecológico... cit., pp. 125 y ss.; ALASTUEY, El delito... cit., p. 71; MARTÍNEZ BUJÁN, C., "Delitos relativos a la ordenación del territorio y la protección del patrimonio histórico y del medio ambiente", en Derecho penal. Parte especial, Valencia, 2004, p. 743; ídem,

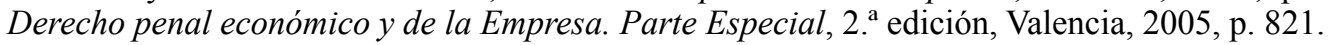


construcción de la protección de la naturaleza se tiene que realizar a partir de "deberes de los hombres respecto a la naturaleza" 36 .

Este referente individual se concreta en una exigencia de subordinación: serán merecedores de tutela penal aquellos ecosistemas que efectivamente son condición esencial del desarrollo humano ${ }^{37}$. Consiguientemente, aunque reconoce la autonomía del medio ambiente, sostiene que esta ratio de tutela individual se ha de plasmar en una necesaria dependencia de su protección de la afectación (lesión o puesta en peligro) de un bien jurídico individual, adicional al medio ambiente ${ }^{38}$. De este modo, si la conducta no es apta para afectar a bienes jurídicos individuales, se solicita una desregulación penal y la asunción exclusiva de competencias por el derecho administrativo sancionador.

\subsection{Perspectiva ecocéntrica moderada}

Este enfoque, el más correcto de todos, reconoce la autonomía del medio ambiente como bien jurídico supraindividual ${ }^{39}$. Mantiene, al igual que el antropocentrismo moderado, un vínculo individual: su ratio de protección reside en que el medio ambiente es condición de desarrollo de los miembros de la sociedad actual y futura ${ }^{40}$.

Ahora bien, su peculiaridad reside en que esta ratio individual de protección no conlleva, como sucede con el antropocentrismo moderado, una demanda de vinculación efectiva con ningún bien jurídico individual. Ello nos sitúa, en la práctica, en el mismo plano que la perspectiva puramente ecocéntrica, al no ser necesaria la lesión o puesta en

\footnotetext{
36 WOHLERS, Deliktstypen... cit., pp. 134 y s. Y no a partir de derechos de la naturaleza. Vid. críticamente supra, nota 26.

37 “[...] el medio ambiente no se puede proteger por sí mismo, sino sólo en tanto que condición necesaria para el desarrollo de la vida humana”, SILVA SÁNCHEZ, “Protección penal...” cit., p. 1715.

38 Vid. ALCÁCER, “La protección del futuro...” cit., p. 29.

39 Vid. BUSTOS RAMÍREZ, J., "Necesidad de la pena, función simbólica y bien jurídico medio ambiente", en Pena y Estado, 1991, p. 104; CORCOY BIDASOLO, "Los delitos..." cit., p. 67; ALASTUEY, El delito... cit., p. 36; BARREIRO, "El bien jurídico..." cit., pp. 15 y ss., 62 y s.; OLMEDO, RODRÍGUEZ, “Artículo 325...” cit., p. 188; MATELLANES RODRÍGUEZ, N., Derecho penal del medio ambiente, Madrid, 2008, pp. 50 y ss.; MENDO ESTRELLA, El delito ecológico... cit., pp. 46, 52. Vid. también a favor de esta autonomía, PORTILLA, "Principio de intervención mínima..." cit., p. 746.

40 Vid. AlASTUEY, El delito... cit., pp. 36 y ss.; CORCOY BIDASOLO, "Los delitos...” cit., p. 67; BARREIRO, "El bien jurídico..." cit., p. 16.
} 
peligro de un bien individual concreto $^{41}$ (la diferencia entre ellas se encuentra únicamente en su fundamentación).

Existe un riesgo de confusión entre antropocentrismo y ecocentrismo moderado. Está causado por la identidad entre ambas perspectivas en la autonomía del bien jurídico y en su conexión con el individuo (presente o futuro) como ratio de tutela. Cuando únicamente atendemos a estos aspectos se suele crear una sola categoría que unifica los dos enfoques de forma indiferenciada bajo la denominación: antropo-ecocéntrico, ecológico-antropocéntrico, o, simplemente, mixto ${ }^{42}$. El criterio de distinción reside en si, a partir de esos puntos de partida, asocian necesariamente la protección penal con un bien jurídico individual (antropocéntrica moderada) o mantienen el referente individual meramente como ratio de protección (ecocéntrica moderada). Es posible, por tanto, que haya autores que, aunque afirmen que tienen un enfoque antropocéntrico moderado, se encuentren, según la interpretación que aquí defiendo, en un plano ecocéntrico moderado, al no vincular la tutela del medio ambiente a un bien individual.

Se sostiene que la CE en su artículo 45, al establecer el derecho a disfrutar de un medio ambiente adecuado al desarrollo de la persona y fijar la obligación de los poderes públicos de velar por la utilización racional de todos los recursos naturales con el fin de proteger y mejorar la calidad de la vida, está tomando partido por una concepción antropocéntrica moderada ${ }^{43}$. Ello, empero, no es tan evidente. También se debe tener en cuenta la referencia a la "solidaridad colectiva" y al "uso racional de los recursos".

\footnotetext{
${ }^{41}$ Vid. ALASTUEY, El delito... cit., p. 42; BARREIRO, "El bien jurídico...” cit., p. 45.

42 Vid. DE LA MATA BARRANCO, Protección penal... cit., p. 54; REGIS PRADO, "El ambiente..." cit., p. 122. Ello es lo que sucede mayoritariamente en Alemania, vid. KUHLEN, "Umweltstrafrecht..." cit., p. 703; KÜHL, "Anthropozentrische..." cit., p. 261; BLOY, "Umweltstrafrecht..." cit. pp. 580 y s.; STEINDORF, Umweltstrafrecht cit., marg. vor 324/15 y ss.; KINDHÄUSER, "Elementos..." cit., p. 502; VÖHRINGER, "Anthropozentrische..." cit., p. 15; MÜLLER-TUCKFELD, "Ensayo..." cit., p. 510; RANSIEK, A., Nomos Kommentar zum Strafgesetzbuch, Baden-Baden, 2000, marg. vor 324/7; CRAMER, P., HEINE, G., Strafgesetzbuch. Kommentar (Schönke/Schröeder), 27. a edición, Múnich, 2006, marg. vor 324/8; LACKNER, K.; KÜHL, K., Strafgesetzbuch, 26. ${ }^{a}$ edición, Múnich, 2007, marg. vor 324/7; WESSELS, J.; HETTINGER, M., Strafrecht. Besonderer Teil, vol. I, 28. a edición, Heidelberg, 2007, marg. 24/1057; OTTO, H., Grundkurs Strafrecht: die einzelnen Delikte, 7.a edición, Berlín, 2005, marg. 82/29; HEFENDEHL, R., "Derecho penal medioambiental: ipor qué o cómo?", en Estudios públicos, n. ${ }^{\circ}$ 110, 2008, p. 15; RENGIER, Strafrecht ... cit., marg. 47/10.

${ }^{43}$ Vid. DE LA MATA BARRANCO, Protección penal... cit., p. 52; SESSANO, "La protección penal..." cit., pp. 19 y s.; BARREIRO, "El bien jurídico..." cit., p. 7; ESCAJEDO SAN EPIFANIO, L., "Manifestaciones de la crisis del estado social en el simbolismo de la protección ambiental", en IeZ: Ingurugiroa eta zuzenbidea $=$ Ambiente $y$ derecho, $\mathrm{n}^{\circ}$ 5, 2007, p. 37. Mantienen expresamente que el artículo $45 \mathrm{CE}$ defiende un concepto moderadamente antropocéntrico del medio ambiente las SSTS 538/1992; 1638/1994; 105/1999; 1725/2002; 1828/2002.
} 
Ambas se relacionan más fácilmente con una línea ecocéntrica ${ }^{44}$, que, desde luego, tiene que ser moderada a la vista de las citadas menciones al individuo. En realidad, parece que la Constitución hace referencia a la categoría mixta que acabo de mencionar: establece, a partir de la autonomía del medio ambiente, una relación de este con el individuo. Ello implica, desde luego, un rechazo implícito de las versiones radicales de las perspectivas expuestas, pero da cabida a las moderadas ${ }^{45}$.

\subsection{Perspectiva administrativa: modelo de gestión medioambiental}

Hay una quinta opción, la que identifica el bien jurídico medio ambiente con la función que desarrolla ${ }^{46}$ : el modo o modelo de gestión medioambiental (en su relación con el desarrollo económico y el sujeto individual) marcado por la Administración ${ }^{47}$; las facultades en la ordenación y tutela del medio ambiente que tiene la Administración; el interés de control de la Administración sobre los comportamientos contaminantes ${ }^{48}$.

Se le acusa a este planteamiento de expresar una confusión: entre el bien jurídico medio ambiente y el modelo de gestión medioambiental ${ }^{49}$. Y, además, de ser formalista ${ }^{50}$ : al desligarse del objeto real del medio ambiente conduce a un injusto penal que persigue conductas que son una simple desobediencia de la normativa administrativa y cuyo desvalor se basa en ser “disfuncionales”. Por tanto, sería posible volver a un modelo en el que conductas con una peligrosidad insignificante podrían ser sancionadas por un

\footnotetext{
44 Vid. MATELLANES, Derecho penal... cit., pp. 38 y ss.; MENDO ESTRELLA, El delito ecológico... cit., pp. 51 y ss.

45 Vid. OLMEDO, RODRÍGUEZ, “Artículo 325...” cit., p. 173.

${ }^{46}$ Al respecto, vid. BUSTOS RAMÍREZ, "Necesidad de la pena...” cit., pp. 101 y ss.

47 Vid. SEELMANN, K., “Atypische Zurechnungsstrukturen im Umweltstrafrecht”, en Neue Juristische Wochenschrift, 1990, p. 1260 (en ello se convierte el medio ambiente cuando se interpreta como bien jurídico intermedio).
}

48 Vid. MATELLANES, Derecho penal... cit., pp. 74 y s., que identifica (con el objetivo de excluirlas del ámbito típico) las normas que contienen una exigencia de autorización con una concepción formal del medio ambiente: facultades de organización y control del Estado de las actividades contaminantes y peligrosas.

49 Según BARREIRO ("El bien jurídico...” cit., p. 52) supone "entremezclar el interés medio ambiente” y "el modelo legislativo y de control administrativo".

50 Vid. RENGIER, "Zur bestimmung..." cit., p. 2509 que denomina expresamente a este planteamiento como administrativo-formal. Vid. también SILVA SÁNCHEZ, “Protección penal...” cit., p. 1715 y nota 15; BARREIRO, “El bien jurídico...” cit., p. 39; MATELLANES, Derecho penal... cit., pp. 75 y s. 
derecho penal que asume las competencias del derecho administrativo sancionador, que, según el principio de fragmentariedad y última ratio, parece la entidad más competente ${ }^{51}$.

Estos reproches deben ser aclarados:

(1) Como ya he dicho, siempre existe una relación material con el bien jurídico medio ambiente. Cualquier acción que vulnera la función de gestión (organización y control) presenta una relación de ofensividad con el bien jurídico (y viceversa) ${ }^{52}$. De hecho, esta actividad de gestión tiene como principal objetivo la protección del medio ambiente ${ }^{53}$. Además, recordemos que el ámbito de lo permitido en las relaciones con el bien jurídico medio ambiente está condicionado por los límites marcados por el modelo de gestión.

(2) La esencia de la crítica se halla en que, cuando se opta por esta perspectiva, hay una renuncia a someterse al bien jurídico como límite externo aunque siempre exista una conexión con él. Esto se plasma en un cambio en el criterio de medición de la relación de ofensividad: no se construye sobre la idea de lesión, sino de disfuncionalidad; entendiendo, asimismo, que se produce cuando hay una negación, cualquiera, de la normativa reguladora del modelo de gestión. Esta negación genera una pérdida de confianza en la función social o defraudación de la expectativa de la continuidad de dicha institución. Ello posibilita dos situaciones.

(2.1) Podrían ser objeto de sanción penal algunas conductas "que desde una perspectiva material del injusto vinculado al fin superior de protección de bienes jurídicos [solo] podrían entenderse como un ilícito formal" 54 , por el carácter insignificante del ataque al

51 En suma, se produce una confusión entre derecho administrativo y penal: hasta el punto que la referencia "penal" que este segundo contiene sería una mera etiqueta, STRATENWERTH, “Zukunftssicherung..." cit., pp. 685 y s.

52 Vid. RENGIER, “Zur bestimmung...” cit., pp. 2514 y s.; PALAZZO, F., "Principios fundamentales y opciones político-criminales en la tutela penal del ambiente en Italia", en Revista Penal n. ${ }^{\circ}$ 4, 1999, pp. 76 y ss.

53 Vid. RENGIER, “Zur bestimmung...” cit., p. 2509.

${ }^{54}$ FUENTES, “Formas de anticipación...” cit., pp. 2 y s. 
medio ambiente que representan ${ }^{55}$. Este efecto se podría intentar evitar exigiendo que solo se sancionará por la vía penal comportamientos que impliquen una negación grave del modelo de organización y control ambiental estatal (disfuncionalidad grave).

No obstante, pese a esta corrección, aún sería posible afirmar que cualquier contaminación provoca una disfuncionalidad grave en ciertos casos. Por ejemplo, siempre que exista un riesgo adicional de repetición ${ }^{56}$. Esto permite justificar la persecución penal de comportamientos con un contenido material de injusto muy reducido pero que pertenecen a una clase de conductas sobre las que existe un riesgo de repetición, que ya representan un atentado grave contra el modelo de gestión del medio ambiente.

Ahora bien, el criterio de la "disfuncionalidad" no conduce siempre a la situación anteriormente descrita: también se pueden considerar disfuncionales conductas que, en relación con el bien jurídico, poseen una peligrosidad muy elevada e incluso representan puestas en peligro y lesiones graves.

(2.2) Una interpretación en este sentido del bien jurídico justificaría la impunidad de comportamientos que, aunque amparados por una autorización formalmente válida, representan una vulneración de la normativa material ${ }^{57}$.

\section{Elementos que incluye el medio ambiente como bien jurídico autónomo}

La específica función protectora del medio ambiente desde un encuadre que reconoce su autonomía requiere, como ya he indicado, fijar la extensión de un bien jurídico que en su versión más vasta llega a comprender todo el planeta y todos los elementos que incluye.

Este enfoque tan amplio dificulta la actividad penal en la tutela del medio ambiente. Implica que cualquier conducta puede representar una agresión al medio ambiente, pero,

\footnotetext{
${ }^{55}$ Vid. WOHLERS, Deliktstypen... cit., pp. 135, 140; FUENTES, "Formas de anticipación...” cit., pp. 23 y s.

${ }^{56}$ Vid. críticamente ALCÁCER, “La protección del futuro...” cit., pp. 19 y ss.

${ }^{57}$ Vid. WOHLERS, Deliktstypen ... cit., pp. 135, 140.
} 
al mismo tiempo, que toda agresión, a la vista de la extensión del bien jurídico, debería ser penalmente irrelevante al suponer una lesión insignificante: ni conlleva, ni tiene capacidad para ello, un colapso o una afectación grave del medio ambiente planetario.

Sin embargo, el derecho penal no tiene por qué actuar con un bien jurídico que tenga esas dimensiones. Puede decidir efectuar una serie de restricciones en su extensión que faciliten el manejo de este bien en la relación de ofensividad.

Según defiendo, estas limitaciones se realizarán en tres niveles consecutivos:

(i) En primer lugar se determinará si el bien jurídico medio ambiente se va a construir limitado a los medios y/o manifestaciones ambientales en sentido estricto o si va a integrar otras cuestiones del entorno ambiental, especialmente los elementos culturales y territoriales.

(ii) La siguiente reducción consistirá en establecer, dentro del grupo de elementos recogidos por este bien, el tamaño del ecosistema tutelado.

(iii) Finalmente se tendrá que decidir qué nivel de agresión (colapso, afectación grave, simple afectación) será el momento consumativo a efectos penales de la lesión del medio ambiente.

La primera reducción la analizaré en el estudio del bien jurídico. Las otras dos, en cambio, al determinar la estructura del injusto. 
La ordenación de los elementos abarcados por el bien jurídico medio ambiente se ha presentado habitualmente de tres formas ${ }^{58}$ :

(1) Un primer planteamiento insiste en que debe detenerse únicamente en la protección de los elementos abióticos que lo componen: el suelo, el aire y el agua. Es una perspectiva estricta (física) del bien jurídico medio ambiente que excluye cuestiones relativas al territorio y a los factores bióticos ${ }^{59}$.

(2) Una segunda acepción, no tan estricta, aumenta el ámbito de protección a los elementos bióticos y abióticos. Es una concepción intermedia (física y biológica) del bien jurídico medio ambiente que incluye el mantenimiento de las cualidades del suelo, aire y agua, la protección de la fauna y flora, y la utilización racional de los recursos naturales ${ }^{60}$.

(3) En tercer lugar aparece una versión que extiende la protección a la ordenación territorial y al patrimonio histórico-artístico. Es un enfoque amplio o global del medio ambiente: incluye todo el entorno que rodea al hombre y que condiciona su

\footnotetext{
58 Vid. LÓPEZ RAMÓN, F., "El Derecho Ambiental como Derecho de la Función Pública de protección de los recursos naturales", en Valle Muñiz (coord.): La protección jurídica del medio ambiente, Pamplona, 1997, pp. 109-112; BLANCO LOZANO, C., La protección del medio ambiente en el derecho penal español y comparado, Granada, 1997, pp. 18 y ss.; ALASTUEY, El delito... cit., p. 55; BARREIRO, "El bien jurídico...” cit., pp. 4 y ss.; REGIS PRADO, "El ambiente...” cit., pp. 119 y s. Vid. también GIANNINI, M. S., “Ambiente: saggio sui diversi suoi aspetti giuridici”, en Rivista Trimestrale di Diritto Pubblico, 1973, pp. 23 y ss. que de forma parecida, pero mezclando varios aspectos de los que se indican, distingue tres planos de ambiente: paisaje (foresta, parques naturales, belleza panorámica, centros históricos); defensa del suelo, aire y agua (que comprende la flora y la fauna); urbanismo (vinculado a la potestad de planificación territorial de la Administración).

${ }^{59}$ Así BLANCO LOZANO, C., El delito ecológico. Manual operativo, Madrid, 1997, pp. 105 y s.

60 Vid. DE LA CUESTA AGUADO, “Algunas consideraciones...” cit., pp. 276 y ss.; DE LA MATA BARRANCO, Protección penal... cit., p. 50; CONDE-PUMPIDO, "La tutela del medio ambiente..." cit., p. 1551; LÓPEZ RAMÓN, "El derecho ambiental..." cit., p. 109; DE LA CUESTA ARZAMENDI, "Delitos contra..." cit., p. 292; GARCÍA RIVAS, Delito ecológico... cit., p. 126; "Juicio crítico sobre las reformas penales en materia medioambiental introducidas por la Ley Orgánica 15/2003, de 25 de noviembre, de reforma del Código Penal", en La ley penal: revista de derecho penal, procesal y penitenciario, n. ${ }^{\circ}$ 6, 2004, p. 17; SESSANO, "La protección penal..." cit., pp. 19 y s.; ALASTUEY, El delito... cit., p. 57; CARMONA SALGADO, C., "Delitos contra los recursos naturales, el medio ambiente, la flora, la fauna y los animales domésticos. Disposiciones comunes", en Cobo del Rosal (coord.): Derecho Penal Español. Parte Especial, 2." edición, 2005, p. 697; BARREIRO, "El bien jurídico..." cit., pp. 5, 60; MATELLANES, Derecho penal... cit., p. 41. Vid. también en el ámbito alemán CRAMER, HEINE, Strafgesetzbuch... cit., marg. vor 324/8; LACKNER, KÜHL, Strafgesetzbuch... cit., marg. vor 324/7; WESSELS, HETTINGER, Strafrecht... cit., marg. 24/1057; RENGIER, Strafrecht... cit., marg. 47/10.
} 
desarrollo. Abarca los aspectos sociales, económicos, culturales e históricos, así como el territorio y el urbanismo, e incluso la salud (salubridad) ${ }^{61}$. Esta óptica llevaría, en su interpretación más radical, a insertar prácticamente todo dentro del concepto de bien jurídico medio ambiente, de manera que se establecería un bien jurídico cuyos contornos estarían en continua expansión, con ilimitadas formas de agresión (que en su extremo provocaría que cualquier conducta lesiva de otro bien jurídico fuera al mismo tiempo lesiva del medio ambiente) ${ }^{62}$. Por este motivo esta visión amplísima del medio ambiente únicamente se debería sostener como ratio de protección: cada uno de los factores señalados forman parte del ambiente que condiciona positiva o negativamente las posibilidades, presentes y futuras, de vida humana digna y libre.

Los elementos que finalmente se decidan incluidos serán objetos materiales del bien jurídico medio ambiente ${ }^{63}$. Ahora bien, debo precisar que son parte del bien jurídico pero no el bien jurídico medio ambiente en sentido estricto. Este solo será el sistema natural ${ }^{64}$. Así, por ejemplo, se tendría que afirmar que se protege la flora y la fauna como manifestación de la realidad superior tutelada: el medio ambiente o ecosistema natural, respecto al cual se tiene que realizar el juicio de ofensividad.

61 Vid. GIANNINI, “Ambiente...” cit., pp. 23 y ss. que habla de bienes ambientales culturales. Vid. DE LA CUESTA AGUADO, Causalidad... cit., pp. 56 y s. que distingue entre medio ambiente (factores ecológicos) y ambiente o hábitat humano (factores sociales, culturales, económicos, etc.). Vid. igualmente LOZANO CUTANDA, B., Derecho Ambiental Administrativo, 5. a edición, Madrid, 2004, pp. 78 y s. que considera que el paisaje y sus medios materiales sí pueden integrar el concepto del medio ambiente: "Así, los objetos muebles que integran el Patrimonio Histórico Español — un cuadro declarado de interés cultural, por ejemplo- , no parece que puedan considerarse como objeto de protección jurídica desde la perspectiva del medio ambiente, pero sí en cambio pueden estimarse tutelable desde esta perspectiva ambiental muchos de los bienes inmuebles que integran este Patrimonio, como los monumentos, los jardines, conjuntos y sitios históricos, o las zonas arqueológicas”. En contra LÓPEZ RAMÓN ("El derecho ambiental..." cit., p. 112), que mantiene que "la función pública de protección del medio ambiente debe ser diferente de otras funciones públicas cuyos objetos están relacionados con la utilización racional de los recursos naturales. Se trata de la ordenación del territorio, el urbanismo, la protección del patrimonio cultural y la tutela de la salud".

62 Vid. BLANCO LOZANO, El delito ecológico... cit., p. 38; REGIS PRADO, “El ambiente...” cit., p. 120.

63 Vid. DE LA CUESTA AGUADO, “Algunas consideraciones...” cit., p. 277; BLANCO LOZANO, El delito ecológico... cit., pp. 85 y s.; ídem, La protección ... cit., p. 213.

64 Vid. DE LA CUESTA AGUADO, “Algunas consideraciones...” cit., p. 278, ídem, Causalidad... cit., pp. 66 y ss.; CORCOY BIDASOLO, "Los delitos...” cit., p. 68; ALASTUEY, El delito... cit., pp. 64; 118; MATELLANES, Derecho penal... cit., p. 44. Vid. igualmente REGIS PRADO, "El ambiente..." cit., p. 122 que distingue entre sustrato del bien jurídico (equilibrio de sistemas naturales) y objeto de la acción (un animal, una planta, el agua del río, etc.). Vid. también BLOY, "Umweltstrafrecht..." cit. p. 580; OTTO, Grundkurs Strafrecht... cit., marg. 82/29. De otra opinión, RENGIER, Strafrecht... cit., marg. 47/10, que reconoce cada uno de estos elementos como "bienes jurídicos ecológicos autónomos". 
No obstante, es cierto que, a medida que se reduce el tamaño del ecosistema, esta distinción, que nunca desaparece, deja de verse con claridad. Cuando se maneja un ecosistema pequeño (por ejemplo, los 100 metros de río afectados por un vertido), la lesión de los medios y las manifestaciones será interpretada en la mayoría de las ocasiones como una lesión del ecosistema. Pero esto no sucederá necesariamente. Podrían plantearse, al menos teóricamente, situaciones en las que no ocurriera, y ello porque el objeto que se toma como referencia para efectuar el juicio de ofensividad no es la afectación de dichos elementos sino la del ecosistema en su conjunto.

Aunque se defienda, acertadamente, que la concepción intermedia del medio ambiente es la dominante en España ${ }^{65}$ y, en concreto, sea la recogida por el artículo $45 \mathrm{CE}^{66}$, no debe pasar inadvertido que todos los aspectos destacados por la versión amplia son objeto de reconocimiento y tutela. Sin embargo, mientras que su presencia en diversos lugares de la $\mathrm{CE}^{67}$ apoya una interpretación intermedia, su aparición en el mismo título del $\mathrm{CP}^{68}$ arroja dudas sobre si se puede mantener esta interpretación en el ámbito penal. El título XVI del CP se denomina "De los delitos relativos a la ordenación del territorio y urbanismo, la protección del patrimonio histórico y el medio ambiente" 69 . De este modo parece que el CP admite un enfoque amplio o global. Varios factores, empero, siguen sustentando el intermedio: la unión entre equilibrio ecológico y medio ambiente recogida en el capítulo III ("De los delitos contra los recursos naturales y el medio ambiente"); la mención expresa de las manifestaciones del medio ambiente en el capítulo IV ("De los delitos relativos a la protección de la flora, fauna y animales

\footnotetext{
65 Vid. DE LA MATA BARRANCO, Protección penal... cit., pp. 49 y s.; ALMELA VICH, C., "El medio ambiente y su protección penal", en Actualidad Penal, vol. I, n. ${ }^{\circ}$ 2, 1998, p. 27; BARREIRO, "El bien jurídico..." cit., pp. 4 y ss.

66 Vid. DE LA MATA BARRANCO, Protección penal... cit., p. 48.

67 Vid. artículos 45 (protección del medio ambiente), 46 (deber de conservación y enriquecimiento del patrimonio histórico, cultural y artístico) y $47 \mathrm{CE}$ (regulación del uso del suelo al servicio de garantizar el derecho a una vivienda digna). Así, PRATS, MARQUĖS, MORÁN, Derecho penal ambiental... cit., pp. 41 y s., defienden que, aunque la CE mantiene un concepto amplio de medio ambiente, una interpretación global de dicho artículo, que tiene en cuenta otros derechos y principios rectores, reduce su extensión, con lo que quedan fuera: "la salud pública y la adecuada utilización del ocio (art. $43 \mathrm{CE}$ ); [...] la conservación del patrimonio artístico (art. $46 \mathrm{CE}$ ); [...] el derecho a la vivienda y por último la utilización del suelo (art. $47 \mathrm{CE}) "$.
}

68 Vid. MATA Y MARTÍN, R. M., "Problemas y eficacia del Derecho penal del medio ambiente (Especial referencia a la contaminación de aguas subterráneas)", en Cuadernos de Política Criminal, n. ${ }^{\text { }}$ 72, 2000, p. 645; MATELLANES, Derecho penal... cit., p. 47.

${ }^{69}$ Modificado por la LO 5/2010, de 23 de junio de 2010, de modificación del Código Penal, que introduce el término urbanismo. 
domésticos”) y su vinculación con el equilibrio de los sistemas naturales en los tipos concretos ("con grave perjuicio para el medio ambiente", art. $332 \mathrm{CP}$; "de modo que perjudique el equilibrio biológico", art. $333 \mathrm{CP}$ ); la ausencia de conexión expresa entre las conductas típicas de los capítulos I y II ("De los delitos sobre la ordenación del territorio y el urbanismo"70; "De los delitos sobre el patrimonio histórico") y el equilibrio de los sistemas naturales ${ }^{71}$.

Desde un planteamiento intermedio, y en función de lo que acabo de indicar, se censura a la regulación penal actual la falta de referencia en el delito ecológico a los elementos bióticos y la ausencia de conexión expresa con el equilibrio ecológico en los delitos contra la fauna (arts. 334-336 CP). No obstante, tanto en el delito ecológico como en los delitos contra la flora y la fauna se tutela un medio ambiente que incluye elementos bióticos y abióticos. Si bien, en el segundo caso, hay una especificación de su manifestación: ataques extremos contra la diversidad biológica, que han de resolver su conexión con el delito ecológico mediante el concurso de leyes ${ }^{72}$. En realidad, tras este primer comentario se esconden otros dos reproches: el que sostiene que los delitos contra la flora y la fauna deberían haberse incluido en el capítulo relativo a los "Delitos contra los recursos naturales y el medio ambiente" y no en un capítulo independiente ${ }^{73}$; y el que plantea que esta dispersión de la tutela medioambiental también se observa en

\footnotetext{
${ }^{70}$ Modificado por la LO 5/2010, de 23 de junio de 2010, de modificación del Código Penal, que introduce el término urbanismo.

71 Posiblemente con la excepción del artículo 330 CP. CARRASCO ANDRINO, M. M., "El daño a los elementos de un espacio natural protegido: un nuevo ilícito penal", en Morales Prats, F.; Quintero Olivares, G. (coord.): El nuevo derecho penal español: estudios penales en memoria del profesor José Manuel Valle Muñiz, Elcano, 2001, p. 1090, mantiene que el artículo 330 CP se puede considerar "especialmente referido a los elementos bióticos y abióticos que determinan la declaración de espacio natural protegido [...]. Una segunda posibilidad supone ampliar este contenido natural del bien jurídico protegido con la inclusión de los valores culturales, científicos, etc. que fundamentan la declaración de especial protección. A favor de ello se encuentra el que el tipo de injusto consista en dañar gravemente alguno de los elementos (naturales o culturales) que hayan servido para calificar al espacio como protegido. El legislador no sólo no ha limitado a los naturales elementos a los que se refiere el daño grave, sino que, además, ha establecido como condición típica, que sea uno de los que han servido para fundar la declaración de espacio protegido y [...] en el concepto de espacio natural protegido tienen cabida, además de los valores naturales, los culturales, por los que por ejemplo, los Paisajes protegidos se hacen acreedores de especial protección".
}

72 A favor del artículo 325 CP por alternatividad, de manera que los artículos 332 y ss. CP asumen un papel subsidiario: serán aplicables cuando no se cumplan los requisitos (especialmente la forma de contaminación típica) del delito ecológico.

73 Vid. DE LA CUESTA ARZAMENDI, "Delitos contra...” cit., p. 291; SESSANO, "La protección penal..." cit., pp. 27 y s.; MATELLANES, Derecho penal... cit., pp. 52 y s. 
otras partes del $\mathrm{CP}^{74}$, lo que conduce a solicitar la creación de un título que abarque todos los delitos contra el medio ambiente, no solo los que afectan a los recursos naturales y a la flora y fauna, sino también los delitos de incendios y de riesgo catastrófico ${ }^{75}$.

Respecto a los delitos contra la flora y la fauna, no solo habría sido posible integrarlos en el capítulo III mediante una mención expresa. Igualmente se podría afirmar que esta mención es innecesaria ya que el atentado contra la flora y fauna, sobre todo cuando son especies amenazadas, puede producir una alteración grave del equilibrio de los sistemas naturales que, en los supuestos de peligro de extinción, incluso podría ser objeto de sanción por la vía agravada del artículo $326 \mathrm{CP}$ por el resultado catastrófico e irreversible que represente o pueda representar.

\section{ESTRUCTURA TÍPICA Y DEL INJUSTO}

La estructura del tipo y del injusto va a depender de la definición del bien jurídico que la perspectiva elegida nos proporciona. Así, el injusto del delito medioambiental se construirá de forma diferente en cada versión radical: el encuadre antropocéntrico exige que la conducta lesione un bien individual o que lo ponga en peligro; el ecocéntrico, que produzca una lesión del ecosistema o que lo ponga en peligro. Como se puede ver, el delito de peligro y el delito de lesión, al poseer un objeto de referencia no coincidente, tendrán, en consecuencia, un significado totalmente diferente en ambos planteamientos.

En suma, cada uno de los enfoques de fijación del contenido del bien jurídico medio ambiente van a conducir a la aparición de estructuras del injusto radicalmente opuestas (versiones radicales) o divergentes pero con elementos de intersección (versiones moderadas) al haber integrado cuestiones de la otra perspectiva.

\footnotetext{
74 Título XVII: De los delitos contra la seguridad colectiva. Capítulo I De los delitos de riesgo catastrófico: 341-350 CP. Capítulo II De los incendios; sección II De los incendios forestales: artículos 352-355 CP.

75 Vid. DE LA CUESTA ARZAMENDI, "Delitos contra..." cit., p. 291; SESSANO, "La protección penal..." cit., p. 30 .
} 


\section{Perspectiva antropocéntrica radical}

No reconoce el medio ambiente como bien jurídico autónomo, es simplemente la referencia a una forma de comisión de un ataque contra un bien jurídico individual. De este modo la estructura del injusto únicamente tiene una vinculación subjetiva, normalmente con la vida o la integridad física. Esto revela dos elementos necesarios.

(1) La presencia de un ataque contra el medio ambiente en la forma descrita por el tipo. No obstante, es irrelevante su grado de ofensa, pues la respuesta penal no depende de ello. Basta la realización de la conducta típica, por ejemplo, efectuar un vertido tóxico.

(2) La agresión a un bien jurídico individual determinado típicamente.

La relación de ofensividad se construye exclusivamente en torno a este bien individual. El nivel de afectación requerido puede ser de lesión o de peligro.

Si no se constatara la presencia de dicho nivel de afectación del bien jurídico individual, la conducta no sería típica ${ }^{76}$ aun cuando haya una afectación del medio ambiente. Si se ha verificado este nivel de afectación, sí se podría sancionar por el delito medioambiental, aunque no haya una afectación del medio ambiente.

El problema que surge a renglón seguido será resolver la relación que se mantiene con las formas consumadas de agresión al bien jurídico individual de referencia.

Si el nivel de afectación del bien individual demandado por el tipo medioambiental fuera de lesión, los concursos de leyes con otros ataques típicos a los mismos bienes individuales se resolverían por especialidad a favor del tipo que tiene incluida la forma específica de comisión medioambiental. Surgiría con ello el debate sobre la cuantía de la pena que debe estar prevista en la comisión de agresiones contra la vida o integridad física mediante actos de contaminación: parece que debería ser igual77 a la recogida en

\footnotetext{
76 Vid. HOHMANN, "Von der Konsequenzen..." cit., p. 85.

${ }^{77}$ No debería ser superior, pues ello representaría aceptar que también se tutela el medio ambiente, lo que sí sería propio del planteamiento antropocéntrico moderado.
} 
los tipos básicos de regulación de estas agresiones. Si fuera inferior, conduciría probablemente a la falta de aplicación del delito ecológico, por ejemplo, ya que el principio de alternatividad permitiría el uso del tipo básico consumado, o a la consideración del delito ecológico como una figura privilegiada de aplicación obligatoria. Si el nivel no fuera de lesión sino de peligro, concreto o abstracto ${ }^{78}$, estas conductas, que se corresponden con supuestos de tentativa e incluso de preparación ${ }^{79}$, entrarían en un concurso de leyes con sus formas consumadas (cuando se produjeran), teniendo que aplicarse estas últimas por consunción, al tiempo que justificaría la previsión de un marco penal inferior al que se recoge en los supuestos de consumación ${ }^{80}$.

No obstante, se puede indicar que el recurso a los concursos de leyes infringe el principio de vigencia ya que el tipo principal (de lesión, por ejemplo) no abarca el carácter indeterminado del ataque a los bienes jurídicos individuales propio del acto contaminante. Para cubrir esta carencia se puede decidir que en estos casos se debe (i) utilizar un concurso ideal de delitos entre el delito de lesiones (sujeto/s específicamente lesionado/s) y el delito medioambiental respecto a todas las personas puestas en peligro que no han sido efectivamente lesionadas. Ahora bien, esta situación podría ser resuelta por el legislador de otra forma, (ii) mediante la creación de una agravante específica, prevista en los delitos contra la vida o integridad física, por la peligrosidad del medio de comisión utilizado: a través de un acto de contaminación que puede afectar a una pluralidad de sujetos. En este caso se aplicaría el tipo principal más esta agravante. Lo que implica una vuelta al concurso de leyes (consunción). Con esta concepción, empero,

\footnotetext{
${ }^{78}$ A favor de esta última opción, HOHMANN, "Von der Konsequenzen...” cit., p. 85.

79 Que impedirían el uso de la teoría general de la tentativa en estos supuestos. No se aplicaría una tentativa de lesiones mediante un vertido, pues esta conducta ya está específicamente sancionada por el artículo $325 \mathrm{CP}$, por ejemplo (estoy resolviendo, así, el concurso de leyes que se plantea por especialidad).

${ }^{80}$ Vid. HOHMANN, “Von der Konsequenzen..." cit., p. 85; VÖHRINGER, “Anthropozentrische...” cit., p. 12.
} 
el delito contra el medio ambiente se transforma, en su versión antropocéntrica, en un delito contra la salud pública ${ }^{81}$.

\section{Perspectiva antropocéntrica moderada}

Como ya he indicado, lo característico de este enfoque reside en que, aunque reconoce el medio ambiente como bien jurídico autónomo, supedita su protección a la lesión adicional de un bien jurídico individual. La estructura del injusto exigirá, por tanto, la afectación copulativa de ambos bienes jurídicos.

Junto a esta opción copulativa también se puede apreciar una disyuntiva: basta la afectación del medio ambiente o de la vida o la integridad física (concurrencia alternativa de ambas agresiones $)^{82}$. El problema es que de este modo hemos abandonado la variante antropológica moderada. Se produce la superposición de una concepción ecocéntrica y una antropológica radical, que se activan alternativamente según cuál haya sido el bien jurídico efectivamente agredido ${ }^{83}$.

Si la concurrencia alternativa se establece entre un planteamiento ecocéntrico y uno antropocéntrico moderado ${ }^{84}$, se crea una relación disyuntiva en la que domina el carácter ecocéntrico: si no se constata la afectación del medio ambiente, no se podrá aplicar el tipo. Ello va a reclamar la creación de dos marcos penales para cada una de las alternativas. Si solamente hubiera uno, surgiría la siguiente pregunta: ¿por qué la afectación adicional de la integridad física de terceros no se tiene en cuenta para incrementar el desvalor de la conducta, superior a la que se limita a afectar al medio ambiente?

Tampoco debe confundirse este enfoque con una variante del ecocentrismo moderado que mantiene una relación con el bien individual como condición objetiva de punibilidad. Esta vinculación no afecta a la estructura del injusto, que depende, exclusivamente, de la relación con el medio ambiente como bien jurídico autónomo. En

\footnotetext{
${ }^{81}$ Lo que representa la entrada en escena de otro bien jurídico. A no ser que la salud pública se entienda como la suma de las saludes individuales. Y en este sentido ya no se podría hablar de bien jurídico colectivo, al ser "susceptible de división en partes atribuibles individualmente, sobre las que se reconozca libertad de disposición", SOTO NAVARRO, "Concreción y lesión..." cit., p. 887; ídem, SOTO NAVARRO, S., La protección penal de los bienes colectivos en la sociedad moderna, Granada, 2003, pp. 198 y ss.

82 Vid. SILVA SÁNCHEZ, Delitos... cit., pp. 97 y ss.

${ }^{83}$ Lo que requeriría a su vez un concurso (ideal) de delitos cuando ambas concurrieran de forma conjunta, vid. SILVA SÁNCHEZ, Delitos... cit., pp. 97 y s.

${ }^{84}$ Vid. FARALDO CABANA, “El delito de establecimiento...” cit., pp. 7 y s.
} 
la antropocéntrica, en cambio, se afirma realmente que el bien jurídico referente del injusto es el individual (estructura del injusto), mientras que el medio ambiente actuaría como bien jurídico intermedio (estructura típica) ${ }^{85}$.

Se tiene que definir el grado de afectación de ambos bienes jurídicos: lesión o peligro abstracto/concreto del medio ambiente y del bien jurídico individual. Si no concurre el nivel de afectación exigido de los dos bienes jurídicos, el comportamiento será atípico, incluso cuando haya una afectación grave del medio ambiente. $\mathrm{Si}$, en cambio, se demuestra concurrente el nivel de afectación, respecto a ambos bienes, entonces sí se podría sancionar por el delito ecológico, por ejemplo. Esta doble relación de ofensividad complica la aplicación del derecho penal medioambiental al incorporar los inconvenientes propios de la relación de ofensividad de cada bien jurídico.

A continuación habrá que resolver la relación que esta construcción mantiene con las formas consumadas de agresión al bien jurídico individual de referencia. En principio se tendría que solventar esta concurrencia de forma parecida a como se ha planteado en el enfoque antropológico radical. Tras esta presunta apariencia se descubren importantes peculiaridades. Si se exigiera la lesión del bien jurídico individual, la pena del tipo medioambiental específico debería ser mayor a la del tipo básico que regula las lesiones contra los bienes individuales, pues, en cuanto delito pluriofensivo, contiene igualmente una agresión contra el medio ambiente.

La relación con las figuras consumadas de los bienes jurídicos individuales será de concurso de leyes, por consunción, a favor del delito medioambiental cuando el nivel de afectación del bien individual requerido en este tipo fuera de lesión. Optar por el delito de lesiones consumado dejaría de tener en cuenta la agresión sufrida por el medio ambiente.

Ahora bien, cuando el nivel de afectación del bien individual no se situara en la lesión y se produjera un resultado lesivo, el concurso de leyes, ya fuera a favor del tipo medioambiental específico, ya fuera a favor del básico de lesiones, representaría una

85 Vid. SEELMANN, “Atypische Zurechnungsstrukturen...” cit., p. 1259. Bien jurídico intermedio: subordinación de bienes jurídicos colectivos a bienes individuales — que responden a unas características comunes de homogeneidad o situación en una misma línea de ataque- mediante la previsión típica de su puesta en peligro en el tipo, vid. MATA Y MARTÍN, R.M., Bienes jurídicos intermedios y delitos de peligro, Granada, 1997, pp. 22 y ss. 
infracción del principio de vigencia: en un caso no se habría desvalorado la agresión superior a la integridad física y, en otro, el ataque autónomo al medio ambiente. La decisión correcta, por este motivo, sería aplicar un concurso ideal de delitos entre el delito de lesiones y el delito medioambiental. El problema reside ahora en la infracción del non bis in idem, ya que se estaría sancionando dos veces la conducta en relación con el bien jurídico individual: por su capacidad lesiva en tal sentido del acto de contaminación y por la concreción de esta capacidad en una lesión efectiva. La solución podría encontrarse en una vuelta al concurso de leyes mediante la creación de una agravante específica de atentado contra la vida e integridad física mediante un acto de contaminación. El motivo no sería la capacidad de afectar a una pluralidad de personas, como se ha planteado desde el enfoque antropocéntrico radical, sino la que tiene respecto al medio ambiente. No obstante, también se puede resolver afirmando que no se vulnera el principio del non bis in idem porque el concurso ideal se plantea con relación a todos los sujetos puestos en peligro que no han sido efectivamente lesionados. Otra vez aparece, con ello, un posible nuevo bien jurídico: la salud pública.

Con todo, la dificultad, en el ámbito penal, común al planteamiento antropológico radical y moderado se halla, primero, en comprobar que existe un menoscabo del bien jurídico individual de referencia; segundo, en demostrar que ha sido causado por dicha conducta contaminante ${ }^{86}$. Última cuestión especialmente difícil de probar, lo que limita las posibilidades de aplicación de los tipos. Para hacer frente a este inconveniente, nos podemos encontrar con tres líneas de actuación:

(1) Se puede considerar que la protección de los intereses individuales es una mera ratio legis (como también lo es su orientación a la tutela de la dignidad y el libre desarrollo de la personalidad), y, por tanto, no es necesario demostrar si hay una auténtica afectación de esos intereses. Ahora bien, cuando se realiza esta afirmación se produce un salto al enfoque ecocéntrico moderado, con una estructura del injusto organizada únicamente en torno a la relación de ofensividad con el medio ambiente.

\footnotetext{
${ }^{86}$ Vid. al respecto BLOY, “Umweltstrafrecht...” cit. pp. 581 y ss.
} 
(2) Es posible requerir la efectiva lesión del bien jurídico individual. Demostrar esta circunstancia se dibuja, empero, como una prueba causal diabólica. Por otro lado, esta demanda también origina una superposición con los tipos que ya regulan los ataques a estos bienes, lo que plantea el problema concursal anteriormente indicado.

(3) Como tercera opción se puede exigir simplemente una relación de peligrosidad o de resultado de peligro respecto al bien jurídico individual trascendente ${ }^{87}$. El delito medioambiental se considera, entonces, un delito de peligro para la vida y la salud de las personas. El objetivo de su creación es precisamente superar los problemas de prueba causal de la lesión o muerte de un sujeto por una conducta contaminadora que arrojan los tipos básicos protectores de los citados bienes jurídicos ${ }^{88}$. Es más fácil acreditar que el comportamiento es potencialmente lesivo (ex ante) de la salud individual (y también se puede decir lo mismo respecto al medio ambiente) que medir ex post el grado de afectación que ha causado dicha conducta en los individuos (y en el medio ambiente) por la concurrencia de diversas variables que influyen en el resultado y que hacen casi imposible seguir el curso causal.

De este modo, el derecho penal medioambiental se construye como una forma de anticipación de la tutela penal que alcanza fases de peligro y de tentativa o preparación $^{89}$ (dolosa e imprudente) y que, además, recuerda en gran medida a los delitos contra la salud pública.

A partir de aquí habría que decidir si se trata de un peligro abstracto o concreto. Este último se enfrenta de nuevo con la dificultad de probar la relación de causalidad entre la conducta contaminadora realizada y un resultado de peligro, lo que lleva a la adopción preferente de la técnica del peligro abstracto. No obstante, la prueba de la capacidad lesiva respecto al bien jurídico individual tampoco es sencilla. Para soslayar esta crítica se recurre a los juicios de peligrosidad diluidos y/o a presunciones sobre la capacidad

\footnotetext{
${ }^{87}$ Vid. SILVA SÁNCHEZ, “¿Protección penal...” cit., p. 1715.

${ }^{88}$ Así BLOY, “Umweltstrafrecht...” cit. p. 581; CORCOY BIDASOLO, “Los delitos...” cit., p. 67.

${ }^{89}$ Insiste en la idea de anticipación y peligro impresa en la concepción antropocéntrica pura, ALCÁCER, "La protección del futuro..." cit., p. 5.
} 
lesiva del comportamiento con relación a grupos de bienes jurídicos individuales $\operatorname{concretos}^{90}$.

El planteamiento antropocéntrico impedirá, en sus dos versiones, la actuación por vía penal en las ocasiones en las que no se pueda demostrar esa relación causal lesiva o la capacidad en tal sentido con el bien individual aunque haya una afectación grave del medio ambiente. Así se establecen mayores niveles de desprotección efectiva frente a agresiones graves al medio ambiente, pues no valora este hecho per se, sino por su conexión causal con un bien jurídico individual ${ }^{91}$.

\section{Perspectivas ecocéntrica radical y moderada}

El enfoque ecocéntrico reconoce el medio ambiente como bien jurídico autónomo. La estructura del injusto se conecta exclusivamente con su menoscabo. La cuestión principal que hay que resolver, para saber si los tipos creados son de lesión o de peligro, será determinar el momento consumativo de un injusto presidido por un medio ambiente entendido de forma autónoma.

(1) Existe una tendencia a afirmar que la protección de los bienes jurídicos colectivos se efectúa a través de delitos de peligro abstracto. Ocurre, casi con certeza, cuando hay una subordinación individual o subjetiva del bien jurídico colectivo. Sin embargo, la construcción de un bien jurídico colectivo autónomo establece una relación de ofensividad para cada comportamiento, independiente y cualitativamente diferente de la relación que tenga, esa misma conducta, con un bien subjetivo. Esto permite definir conductas que serían de peligro en relación con un bien jurídico individual como una auténtica lesión respecto al medio ambiente ${ }^{92}$, lo que excluye en esos casos la

\footnotetext{
${ }^{90}$ Crítico en este sentido SEELMANN, “Atypische Zurechnungsstrukturen...” cit., p. 1259.

${ }^{91}$ Vid. KÜHL, “Anthropozentrische...” cit., p. 255.

92 MATA Y MARTÍN considera que, en relación con dos bienes jurídicos distintos (colectivo/individual), no puede haber "un grado de peligrosidad equivalente" (Bienes jurídicos intermedios... cit., pp. 56-58). Por este motivo defiende, en aquellos supuestos en los que el tipo protege un bien jurídico intermedio o de referente individual, la presencia de delitos de lesión-peligro o peligro-lesión (Bienes jurídicos intermedios... cit., pp. 58, 66, 76, 85). De forma parecida, GARCÍA RIVAS, Delito ecológico... cit., pp. 114,118 y s.
} 
posibilidad de seguir utilizando la categoría "delitos de peligro", que, por consiguiente, tiene un carácter relativo.

(2) Por otro lado, puede que el comportamiento típico, con un bien jurídico colectivo autónomo de referencia, sea a pesar de todo un delito de peligro abstracto ${ }^{93}$. Es decir, otra cuestión diferente es resolver si la conducta tipificada, aparte de que sea un delito de peligro abstracto en función de un posible bien jurídico individual, pueda ser un delito de peligro abstracto o un delito de lesión en relación con un bien jurídico colectivo. La solución de este problema se subordina a la forma de interpretar cuándo hay, a efectos penales, una lesión plena del bien jurídico colectivo ${ }^{94}$. Dos enfoques extremos respecto al medio ambiente:

(2.1) Una concepción estricta, que sustenta que únicamente sucede cuando hay un colapso pleno del bien jurídico (cuando tiene lugar la destrucción del ecosistema en un sentido naturalístico), llegará a la conclusión de que casi ninguna agresión puede producir directamente dicha lesión. Las conductas serán penalmente relevantes como formas de peligro concreto o abstracto (y al mismo tiempo, como fases de su iter criminis: tentativa o preparación) $)^{95}$ y, en la mayoría de las ocasiones, serán comportamientos con una peligrosidad insignificante. La idea del colapso conduce necesariamente a afirmar que los bienes jurídicos colectivos no pueden ser lesionados, salvo en contadas excepciones, por una acción individual, sino por la suma de varias ${ }^{96}$.

(2.2) $\mathrm{Si}$, por el contrario, se mantiene una concepción laxa, que defiende que toda perturbación, por cuanto afecta a la estabilidad del ecosistema, representa normativamente una lesión del bien jurídico, se produce el fenómeno contrario.

\footnotetext{
93 Un delito de peligro abstracto cualitativamente diferente al construido respecto a un bien jurídico individual.

94 Estoy afirmando, por consiguiente, que el resultado penal en el delito medioambiental no tiene que coincidir con el resultado naturalístico.

95 Vid. HEFENDEHL, R., “Debe ocuparse el Derecho penal de riesgos futuros?”, Revista Electrónica de Ciencia Penal y Criminología [en línea], n. ${ }^{\circ} 04-14,2002$, p. 5.

96 Vid. RODRÍGUEZ MONTAÑÉS, T., Delitos de peligro, dolo e imprudencia, Madrid, 1994, pp. 300 y s.; SILVA SÁNCHEZ, La expansión... cit., p. 129; ALCÁCER, "La protección del futuro...” cit., p. 20; HEFENDEHL, “¿Debe ocuparse...” cit., p. 5.
} 
Cualquier comportamiento, por nimio que sea, sería una lesión consumada. Ello permite justificar, sin dificultad, la sanción (como lesión) de conductas que, en lo que atañe al planteamiento del colapso, tendrían una peligrosidad insignificante, pero sobre las que recaía un riesgo de acumulación.

(3) En el análisis del momento consumativo del bien jurídico medio ambiente, esta distinción entre colapso y perturbación como posturas extremas es insuficiente, pues nos conduce a soluciones fácilmente refutables. ¿Acaso no se puede producir el colapso, la destrucción de un ecosistema (por ejemplo, cortando el acceso del agua a las Tablas de Daimiel durante cierto período de tiempo)? Esta pregunta pone de manifiesto un aspecto esencial que no se ha tenido en cuenta. El análisis del momento consumativo de la lesión del medio ambiente requiere la determinación de dos cuestiones previas con las que se conecta: el tamaño del ecosistema al que se hace referencia y los elementos que incluye.

Ya he hecho mención a este segundo punto en el apartado anterior al indicar que el medio ambiente como bien jurídico autónomo debería adoptar una posición intermedia, de manera que el ecosistema de referencia para el tipo penal, con independencia de su tamaño, deberá entenderse limitado a la interrelación entre los organismos vivos y el medio físico en el que se desarrollan. Ahora hay que analizar la importancia del tamaño del ecosistema.

(3.1) Una versión muy amplia del sistema natural, por ejemplo, el que coincide con la tierra (ecosfera) o con una porción menor pero de tamaño relevante (pensemos en un continente o un país), dificulta constatar la presencia de una lesión entendida como colapso del equilibrio del sistema ecológico. Como la lesión no puede consumarse (hay muy pocas conductas que lo hagan ${ }^{97}$ ), habrá que acudir a las figuras del peligro concreto $\mathrm{y}$, sobre todo, abstracto (que además se pueden corresponder con delitos de tentativa).

\footnotetext{
${ }^{97}$ ¡Y que no acontezcan! El delito ecológico (art. $325 \mathrm{CP}$ ) aparece siempre como el ejemplo (junto con el delito de rebelión del artículo $472 \mathrm{CP}$ ) del delito de tentativa más justificado en su existencia. Esperar a que se produzca una lesión (entendida como colapso pleno del ecosistema) puede ser demasiado tarde: exista ya un daño irreparable del objeto material protegido (e incluso, a lo peor, una imposibilidad de actuación penal si se produce, por ejemplo, la destrucción del planeta). Vid. FUENTES, "Formas de anticipación..." cit., pp. 10 y s.; MENDO ESTRELLA, El delito ecológico... cit., pp. 124 y s.
} 
Ahora bien, sucede igualmente que la concurrencia de los factores ecosistema amplio y exigencia de colapso impide en gran medida recurrir a los tipos de peligro. Y es que, aunque la conducta manifieste alguna vez una capacidad lesiva directa elevada, en la mayor parte de las ocasiones se va a mostrar como insignificante ${ }^{98}$. De modo que muchos ataques no se pueden considerar siquiera como un delito de peligro abstracto. En este punto se ha situado buena parte de la discusión dogmática: surge un debate para determinar cómo podemos justificar que ese riesgo insignificante es penalmente relevante y que ese riesgo se ha concretado en el resultado (si hubiera tenido lugar).

(a) Una primera solución ha sido forzar el concepto de peligro abstracto mediante un juicio de peligrosidad diluido que precisa que la relevancia material de la conducta reside en que contiene las mínimas condiciones que se consideran suficientes para producir un daño, porque posee, desde una perspectiva global, las características mínimas que tendría toda acción peligrosa ("peligrosidad abstracta"), o que ese comportamiento pertenece a un grupo de modos de actuar que podrían ser peligrosos en determinadas circunstancias (como pudiera ser la posibilidad de acumulación de conductas del mismo tipo) o que según la experiencia podrían ser peligrosos ("peligrosidad general"). En este contexto se sitúan principalmente los delitos de acumulación ${ }^{99}$.

(b) Otra opción sería, empero, modificar, sin cambiar el tamaño del ecosistema, el momento consumativo, indicando que una perturbación o alteración del equilibrio del ecosistema ya representa una lesión suficiente. Como ya he señalado, no debemos partir de una posición según la cual la simple modificación del ecosistema global sería lesiva. Así planteado, todos, con nuestra simple existencia, estaríamos consumando la lesión del medio ambiente. Se genera, por tanto, un efecto no deseado: la persecución de cualquier conducta estaría justificada (iy como forma de autoría consumada!). Para

\footnotetext{
98 Vid. KUHLEN, “Umweltstrafrecht...” cit., p. 722.

99 Vid. KUHLEN, L., "Der Handlungserfolg der strafbaren Gewässerverunreinigung (§ 324 StGB)”, en $G A, 1986$, pp. 396 y ss., respecto al $\S 324$ StGB: sanciona conductas que ni lesionan ni pueden poner en peligro, concreto o abstracto, el medio ambiente. Concluye: estamos ante un "tipo de acumulación”. Vid. también ALCÁCER, "La protección del futuro..." cit., pp. 10 y s.; 19 y s.
} 
soslayar esta consecuencia, hay que indicar una clase o grado de alteración del equilibrio como momento consumativo. Se insiste entonces en que debe ser una alteración suficiente o grave, que no tiene que representar un colapso del equilibrio del sistema natural analizado, pero ha de ser algo más que una simple afectación ${ }^{100}$. Ello requiere definir qué es alteración suficiente o grave, es decir, determinar cuándo se ha alcanzado ese nivel ${ }^{101}$. Normalmente se suele establecer en función de criterios como la superación de los límites de tolerabilidad ${ }^{102}$. Con todo, la fijación de este límite, en el ámbito penal, exige tener la referencia del ilícito administrativo, como margen inferior de la gravedad, respecto al cual el ilícito penal siempre debe ser más grave.

Esta solución nos traslada en cierta medida a la situación anterior, pero con la peculiaridad de que, al reclamarse la producción de una lesión de menor entidad, será más fácil probar su producción o que una conducta posee capacidad en tal sentido. Esto genera una restricción del ámbito de comportamientos insignificantes y permite convertir algunas conductas peligrosas, normalmente formas de tentativas, en lesiones consumadas (si bien predomina el peligro abstracto frente a la lesión). No obstante, no evita, respecto al ámbito de insignificancia restante, que sea necesario justificar su relevancia penal. La solución consiste en aplicar, de nuevo, un concepto de peligrosidad diluido (lo que se añade al cambio del momento consumativo) o directamente en actuar sobre un segundo factor: acortar el tamaño del ecosistema.

(3.2) Una versión muy reducida ${ }^{103}$ del ecosistema analizado facilita justificar la lesión del medio ambiente, ya que únicamente demanda probar que la conducta contaminante

100 Vid. DE LA CUESTA AGUADO, Causalidad... cit., p. 70; CORCOY BIDASOLO, "Protección penal..." cit., p. 637. El CP de 1995 parece haber aceptado esta opción cuando requiere, para que la conducta sea típica por el artículo $325 \mathrm{CP}$, que "pueda perjudicar gravemente el equilibrio de los sistemas naturales".

101 También cuando se considere que ello acontece cuando se produce una alteración grave de la función ecológica del sistema natural (como subsistema de comunicación sobre el que se apoyan las relaciones intersubjetivas), de modo que ya no puede destinarse a su uso (SOTO NAVARRO, La protección penal... cit., pp. 272 y ss.; ídem, “Concreción y lesión..." cit., p. 915), pues obliga a fijar qué grado de impedimento u obstaculización representa una alteración grave de la función ecológica y, además, cuál es la extensión del ecosistema analizado (elementos incluidos y su tamaño).

102 Vid. SOTO NAVARRO, “Concreción y lesión...” cit., p. 916.

103 Se posiciona expresamente en este sentido DE LA CUESTA AGUADO, Causalidad... cit., p. 247, pp.: "por sistema natural ha de entenderse cada microsistema, o hábitat concreto de una especie de una zona, incluso muy reducida: un río, una ladera, una zona litoral". 
posee el nivel de afectación exigido en una parcela menor. Así, es más fácil determinar que se ha producido el colapso del equilibrio ecológico en una parte del río que en todo el río o que en toda la cuenca hidrográfica ${ }^{104}$. Y todavía más sencillo si no requerimos su colapso sino la alteración de su equilibrio.

Según vamos bajando en la escala de binomios alternativos propuestos (colapso ecosistema amplio; alteración grave del equilibrio - ecosistema amplio; colapso ecosistema reducido; alteración grave del equilibrio - ecosistema reducido; simple modificación - ecosistema amplio o reducido) se puede apreciar:

(a) Un aumento en el número de conductas lesivas: disminuye el número de tipos que pueden calificarse de peligro. Se podría llegar a afirmar en algunas combinaciones que la lesión del bien jurídico - estructura del injusto - coincide, por el grado de reducción del ecosistema, con la lesión del medio o manifestación concreta ${ }^{105}$.

(b) Una merma del ámbito de insignificancia: hay más conductas que, aunque no sean lesivas, presentan una capacidad lesiva directa suficiente.

(c) Una lógica disminución del número de comportamientos que entrarían en la problemática de los delitos acumulativos.

(d) Finalmente, todo ello influye en la relación con el derecho administrativo. La necesidad de introducir cláusulas de notoriedad, como factor de diferenciación entre ilícito administrativo y penal, será mayor cuanto más reducido sea el tamaño del ecosistema y más simple sea el momento consumativo. Y es que cuando se utiliza una estructura del injusto que aumenta el número de conductas consumadas, la distinción

\footnotetext{
104 En este línea parece ir SILVA SÁNCHEZ (Delitos... cit., p. 76) cuando indica que la exigencia de puesta en peligro concreto del equilibrio de los sistemas naturales solo tiene sentido como criterio de distinción entre ilícito administrativo y penal referido (el sistema natural) a pequeños ecosistemas, pero no a grandes.

105 Con palabras de SILVA SÁNCHEZ (Delitos... cit., p. 24): se diría que toda lesión del objeto de la acción provoca una lesión del objeto del bien jurídico.
} 
escalonada entre ambos ilícitos ya no se podrá llevar a cabo a través del modelo peligro abstracto - concreto - lesión, sino que tendrá que hacerse mediante la demanda de una mayor gravedad respecto a lo descrito en el ilícito administrativo.

(4) Es posible combinar una concepción amplia con una concepción reducida del ecosistema. Se puede exigir la producción de un resultado lesivo respecto a un ecosistema menor como requisito de la gravedad de la puesta en peligro concreta del equilibrio del ecosistema más amplio e incluso de la capacidad lesiva de la conducta en tal sentido. La puesta en peligro concreto grave del equilibrio del río en su conjunto o la capacidad del vertido contaminante para ello necesariamente acontecen cuando se ha constatado una alteración grave del equilibrio de una parte del río. Ahora bien, esta presunción, muy presente en algunas interpretaciones del artículo $325 \mathrm{CP}$, olvida que el objeto de referencia del juicio de peligro u ofensividad es diferente, y así podrían darse casos en los que, aunque concurre esa situación lesiva respecto al ecosistema reducido, no representa una puesta en peligro concreto grave del equilibrio del ecosistema mayor o no tiene capacidad para producir ese resultado de peligro. Por tanto, incluso cuando dicha exigencia de alteración grave de un ecosistema reducido venga recogida por el tipo, como objeto concreto de la acción típica (estructura del tipo), parece necesario seguir realizando adicionalmente un juicio de ofensividad en relación con el sistema natural más amplio, en torno al que se construye la estructura del injusto como delito de peligro concreto o abstracto.

(5) Las primeras parejas de la escala de alternativas señaladas ${ }^{106}$ conducen, ante la dificultad de constatar la existencia de una lesión (probabilidad de lesión que se incrementa según se reduce la extensión del ecosistema y se simplifica el momento consumativo), a la necesidad de sancionar las agresiones contra el medio ambiente mediante el recurso a los delitos de peligro (concreto o abstracto).

No obstante, hay comportamientos de peligro abstracto que, a la vista de la extensión del bien jurídico y del momento consumativo elegido, aunque poseen una capacidad lesiva directa, se ha de estimar insignificante: únicamente se muestran capaces de

106 Vid. supra y tabla 3. 
producir por sí mismos una microlesión del bien jurídico, motivo por el cual no deberían considerarse conductas penalmente relevantes ${ }^{107}$. En un sentido estricto, no estaríamos ni siquiera ante un delito de peligro abstracto punible. En estos casos su sanción requiere acudir a un criterio de peligrosidad adicional: el riesgo de sumación ${ }^{108}$. Las demandas de protección del bien jurídico determinan la relevancia penal de conductas que de forma aislada son inocuas o poseen un riesgo insignificante, pero cuya repetición o reiteración podría tener consecuencias lesivas en el bien jurídico protegido ("peligro acumulativo"109). Es lo que se conoce como los "delitos de acumulación"110, y persiguen, por consiguiente, evitar un efecto composición negativo ${ }^{111}$.

El delito acumulativo se puede referir a tres situaciones.

107 Insiste en el carácter lesivo, si bien mínimo, en relación con la escala del bien jurídico protegido MENDOZA BUERGO, B., Límites dogmáticos y político-criminales de los delitos de peligro abstracto, Granada, 2001, pp. 494 y s. Cuestión aparte es que se cree un tipo cuyo supuesto de hecho coincida expresamente con estos comportamientos. Estaríamos entonces ante un "tipo de acumulación" (Kumulationstatbestand), KUHLEN, "Der Handlungserfolg...” cit., p. 399; SAMSON, "Kausalitäts- und Zurechnungsprobleme..." cit., pp. 620, 635.

108 Argumento que se tiene que utilizar tanto para extender el alcance de un tipo como para justificar la creación de un tipo que sanciona expresamente supuestos de acumulación. Vid. KUHLEN, "Der Handlungserfolg..." cit., p. 399; ídem, "Umweltstrafrecht...” cit., pp. 717 y ss.; SAMSON, "Kausalitätsund Zurechnungsprobleme..." cit., p. 620, 635, que hablan de la creación de delitos de acumulación que superen los problemas de justificación de la sanción de estas conductas. Primero, porque dicho "tipo de acumulación" "no exige que una sola conducta provoque una lesión o una puesta en peligro sino que la conducta aislada pertenezca a una clase de conductas que si se realizaran en una gran cantidad provocarían una lesión o puesta en peligro", KUHLEN, "Der Handlungserfolg...” cit., p. 399. Segundo, porque la imputación individual se realizará por la propia conducta, en relación con lo que prevé este "tipo de acumulación".

109 Que incluye el efecto acumulativo en un sentido estricto (la acumulación de vertidos de una sustancia lleva a superar el nivel de toxicidad tolerado) y el efecto sinérgico (al combinar sustancias se produce un efecto nuevo, tóxico), vid. MENDO ESTRELLA, El delito ecológico... cit., p. 138.

${ }^{110}$ Vid. KUHLEN, “Der Handlungserfolg...” cit., pp. 389 y ss.; ídem, “Umweltstrafrecht...” cit., pp. 711 y ss., 716; SAMSON, "Kausalitäts- und Zurechnungsprobleme..." cit., pp. 617 y ss.; BLOY, "Umweltstrafrecht..." cit. pp. 581 y ss.; DE LA CUESTA AGUADO, Causalidad... cit., pp. 214 y ss.; WOHLERS, Deliktstypen... cit., pp. 309 y s.; SANTANA VEGA, La protección penal... cit., pp. 167 y ss.; MENDOZA BUERGO 2001b, pp. 61-65, 490-495; SILVA SÁNCHEZ, La expansión... cit., pp. 129 y ss.; ALCÁCER, "La protección del futuro...” cit., pp. 8-10, 12-16; HEFENDEHL, “Debe ocuparse..." cit., pp. 10 y s.; SILVA DIES 2003, pp. 433 y ss.; FUENTES, "Formas de anticipación...” cit., pp. 25 y ss.; SARRABAYROUSE, E., Medio ambiente y Derecho Penal, Buenos Aires, 2008, pp. 41 y ss. En realidad el riesgo de acumulación se encuentra presente en todas las conductas prohibidas, ya que el efecto de sumación está necesariamente vinculado al objetivo preventivo: evitar la repetición de conductas delictivas.

111 "Se entiende por efecto composición aquellos macroestados de equilibrio — pero también aquellas crisis o procesos dinámicos- que surgen por generación espontánea como consecuencia imprevista o no intencionada de la agregación colectiva del microcomportamiento", GIL CALVO, E., El miedo es el mensaje, Madrid, 2003, p. 165. En esta situación, la racionalidad individual se convierte en irracionalidad colectiva, vid. KUHLEN, "Der Handlungserfolg..." cit., p. 401. 
(i) Si no se ha producido el daño final, resultado de la acumulación, se le imputa al sujeto la práctica de su acción, que posee cierta peligrosidad directa, de escasa importancia (por ello se tendría que afirmar la irresponsabilidad penal del que la realiza), pero que, además, pertenece al grupo de conductas sobre las que existe un riesgo de repetición (responsabilidad por la práctica de un comportamiento que puede causar un daño cumulativo).

(ii) Si se ha producido dicho daño global, se puede decidir que solo se le hará responsable del comportamiento que pertenecía a la clase de conductas cuyo riesgo de acumulación se pretendía evitar.

(iii) Finalmente se puede establecer que este resultado de daño global se imputará al sujeto que efectúa una conducta aislada sobre la que existía ex ante un riesgo conocido de sumación ${ }^{112}$.

Respecto a esta última cuestión, considero que la imputación global en estos casos puede plantear un supuesto de imputación ordinario y no de sumación. Y es que la realización de un número determinado de sucesivas conductas coloca al ecosistema analizado en una situación de fragilidad en la que los comportamientos posteriores sí poseen capacidad suficiente para lesionar de forma penalmente relevante el bien jurídico protegido sin necesidad de acudir al criterio del riesgo de sumación. Por este motivo, solo podemos hablar en un sentido estricto de delitos de acumulación:

Cuando sancionamos a sujetos que llevan a cabo conductas en un contexto de acción en el que no se ha alcanzado la situación límite a partir de la cual cualquier comportamiento presenta una capacidad lesiva grave o incluso pone en peligro concreto o lesiona el medio ambiente. Se sanciona la conducta para evitar la sumación y el tipo

112 Así SAMSON ("Kausalitäts- und Zurechnungsprobleme..." cit., pp. 618 y s.) y BLOY ("Umweltstrafrecht..." cit., pp. 582 y s.) distinguen dos situaciones: se le debe imputar al sujeto concreto simplemente su conducta realizada (Teilerfolgszurechnung) o el resultado final consecuencia de la sumación de todas las conductas concurrentes (Gesamterfolgszurechnung). De forma más precisa, la Teilerfolzugsrechnung puede identificarse con los casos de impunidad (conducta irrelevante por su relación de ofensividad ordinaria con el bien jurídico de referencia sin tener en cuenta su efecto sumatorio posible) o con la posibilidad de sancionar penalmente (si se tiene en cuenta el riesgo de sumación). 
subjetivo se construye sobre el conocimiento $-\mathrm{o}$ el deber de conocimiento- de la posibilidad de sumación ${ }^{113}$.

Cuando sí se ha superado dicho límite y hay un resultado imputable porque la conducta tenía capacidad lesiva respecto al resultado, pero el sujeto que actúa desconocía su auténtica capacidad $^{114}$ (y no podía o debía conocerla), si bien conocía el riesgo de sumación (que es lo que finalmente se le imputa). En caso contrario, cuando actúa con conocimiento de la verdadera capacidad lesiva de la conducta en función de la situación del ecosistema afectado, se le debería imputar el resultado producido por autoría ${ }^{115}$.

Imputación por el resultado final que también tiene lugar, lógicamente, cuando es el mismo sujeto el que realiza todas las acciones aisladamente inocuas; se puede constatar en este caso una unidad de acción; o cuando existiera un acuerdo entre todos los que practicaron los comportamientos, que serán responsables como coautores. El delito acumulativo se caracteriza, por consiguiente, por la concurrencia de una serie de acciones insignificantes efectuadas por diferentes sujetos sin existir un acuerdo entre ellos.

Es posible que un bien jurídico requiera la protección frente al efecto sumatorio. Ahora bien, la sanción de estas conductas debería cumplir varias condiciones fundamentales:

(a) Un requisito previo, el de constatar que hay un problema de acumulación y no de determinación de la extensión del bien jurídico (elementos y tamaño) y del momento consumativo. Puede ser que estemos ante comportamientos que, por ejemplo, sean, respecto a un ecosistema reducido, una forma de lesión de este o tengan capacidad lesiva suficiente en este sentido.

\footnotetext{
113 Y aquí se plantea otra cuestión: es posible que el riesgo de acumulación de conductas "no será normalmente previsible para cada uno de los agentes, pues dependerá de múltiples factores accidentales [...] que escapan a la capacidad de previsión y al dominio de una persona media del sector de la actividad correspondiente", SILVA DIAS, A., "¿Y si todos lo hiciéramos? Consideraciones acerca de la "(in) capacidad de resonancia' del Derecho penal con la figura de la acumulación", en Anuario de Derecho penal y ciencias penales, tomo 56, 2003, p. 465.

114 En la mayoría de los casos el ciudadano no podrá reconocer que ha superado el umbral de lesividad con su conducta, que, así, deja de ser insignificante o de bagatela, vid. WOHLERS, Deliktstypen... cit., p. 142. Vid. también STRATENWERTH, “Zukunftssicherung...” cit., p. 684, que se plantea cómo puede conocer un sujeto los deberes de cuidado que debe respetar en esta situación.
}

115 Próximo vid. SAMSON, “Kausalitäts- und Zurechnungsprobleme...” cit., p. 627. 
En suma, el delito acumulativo tiene un carácter relativo. El delito acumulativo depende, entre otros factores, de la fijación del tamaño del bien jurídico medio ambiente, pues este va a condicionar la extensión del principio de insignificancia ${ }^{116}$ : no es lo mismo determinar la lesión del objeto material del medio ambiente en función de todo el río, por ejemplo, o de una pequeña parte de este ${ }^{117}$. En el primer caso la conducta será normalmente insignificante y su relevancia dependerá de la posibilidad de sumación o de su efectiva sumación a otras similares; en el segundo, en cambio, se podrá constatar con mayor facilidad una lesión o una puesta en peligro concreta, o determinar que la conducta es capaz de producir dicha lesión. De este modo se concluye que se puede manipular la relevancia o irrelevancia de una conducta (por la insignificancia de su ataque al bien jurídico de referencia) mediante la selección del fragmento o porción del objeto material analizado.

(b) Distinguir los supuestos de responsabilidad por riesgo de acumulación de aquellos en los que el sujeto lleva a cabo una conducta que en el estado de cosas conocido (por ejemplo, del ecosistema afectado) posee una capacidad lesiva elevada.

(c) Obligatoria comprobación de que existe un peligro real de efecto de composición negativo $^{118}$ y una necesidad de protección en función de la importancia del bien jurídico protegido.

(d) La conducta, dentro de su insignificancia, debe tener una peligrosidad mínima ${ }^{119}$. En caso contrario, la posibilidad de sanción de comportamientos sería infinita. La fijación de este mínimo se debe realizar en función de las características del acto contaminante

116 Vid. al respecto SAMSON, "Kausalitäts- und Zurechnungsprobleme..." cit., pp. 625, 635 y s.; KUHLEN, "Umweltstrafrecht..." cit., p. 715; BLOY, “Umweltstrafrecht...” cit. pp. 582 y s.

117 Vid. también otros ejemplos respecto a los vertidos en el mar o las emisiones a la atmósfera en SAMSON, "Kausalitäts- und Zurechnungsprobleme..." cit., p. 625.

118 Vid. WOHLERS, Deliktstypen... cit., pp. 322 y ss., que distingue entre las situaciones donde dicho efecto es científicamente conocido (delitos de contaminación ambiental) y aquellas en que no lo es (fraude de subvenciones, por ejemplo).

119 Vid. WOHLERS, Deliktstypen... cit., pp. 324 y ss. 
(nivel de toxicidad de las sustancias, cantidad, permanencia, etc.) y en función del riesgo real de sumación. Cuanto mayor sea este riesgo, menor podrá ser la peligrosidad requerida, si bien asumiendo que el derecho penal estará desplazando al derecho administrativo (y pondrá en cuestión el principio de ultima ratio).

(e) La fijación de una sanción proporcional a la gravedad de la conducta efectuada y a la prevista para otras formas de agresión más graves de dicho bien jurídico, respecto a las cuales la sanción establecida para el delito de acumulación no debe ser superior.

(6) Los planteamientos ecocéntricos (radicales y moderados) aseveran:

(i) Que no se tiene que exigir a la conducta que atenta contra el medio ambiente ninguna capacidad lesiva respecto a la vida e integridad física.

(ii) Que la relevancia típica del comportamiento se establece siempre en la relación de ofensividad que la conducta enjuiciada presenta respecto al equilibrio del ecosistema.

(iii) Que en el caso de que la conducta contaminadora tuviera una adicional relación de ofensividad con un bien individual, se podría resolver esta situación acudiendo al concurso de delitos (ideal) entre el delito ecológico y los delitos efectivamente producidos contra la vida o la integridad física.

Sería posible convertir esa relación de ofensividad con el bien individual en un elemento accidental, en un sentido agravatorio, situado dentro de los tipos relativos al medio ambiente.

Si esta agravación coincidiera con la lesión del bien individual, el conflicto se resolvería por un concurso de leyes a favor del tipo medioambiental (consunción). Ahora bien, esta solución dejaría sin sancionar la capacidad lesiva que posee la conducta para afectar a 
un número indeterminado de personas que, finalmente, no han sido lesionadas. Se podría recurrir, entonces, a un concurso ideal entre el tipo medioambiental agravado y el delito contra la salud pública a través de una agresión medioambiental (siempre que exista semejante tipo). El problema que plantearía esta solución se halla en la posible doble imputación de un atentado contra el medio ambiente. Razón que aconsejaría utilizar, de nuevo, el concurso de leyes mediante la creación de una nueva agravante que recoja esta posibilidad. De este modo habría un tipo medioambiental con dos agravantes: por la capacidad lesiva indeterminada y por la lesión al bien jurídico individual producida.

Si la agravación se identificara, en cambio, con una puesta en peligro de los bienes individuales y se produjera adicionalmente su lesión, habría que aplicar un concurso ideal entre el tipo básico y las lesiones concretas. No obstante, el concurso ideal sería entre el tipo agravado y las lesiones si mantenemos que también tutela la salud pública (ya que la construcción del concurso con el tipo básico dejaría de tener en cuenta este aspecto: solo atendería a la afectación medioambiental).

\section{CONCLUSIONES}

(1) No se puede afirmar que en los delitos contra el medio ambiente, desde el punto de vista de la relación de ofensividad, toda la problemática se tenga que reducir a la disyuntiva entre delitos de peligro concreto y abstracto.

(2) Previamente hay que establecer la definición bien jurídico medio ambiente. Se puede optar por una definición individual del bien jurídico (antropocentrismo). En este caso, la mayoría de los tipos creados serán de peligro: intentan superar los problemas causales que surgen a la hora de demostrar que un acto de contaminación ha sido el causante de la lesión de la vida o integridad física de un sujeto. Desde este punto de vista no se tutela el medio ambiente (antropocentrismo radical) o, al menos, su protección se encuentra condicionada (en la forma de un bien jurídico intermedio) a la existencia, necesaria, de una puesta en peligro de un bien jurídico individual (antropocentrismo moderado). 
Sin embargo, se puede dar una definición colectiva del bien jurídico medio ambiente, que así se presenta de forma autónoma: no tiene asociación necesaria alguna con el bien individual (ecocentrismo). Cuando esta sea la decisión, la estructura del injusto se elabora únicamente teniendo como referencia la lesión de los ecosistemas. Puede incluir la afectación de la vida o integridad física como un elemento accidental agravatorio.

Lo expuesto se puede ver más claro en la siguiente tabla:

\section{Tabla 1}

Carácter necesario de la relación de ofensividad con el bien jurídico medio ambiente (autónomo) y/o con un bien jurídico individual según una concepción ecocéntrica o antropocéntrica

A NTROPOCÉNTRICA

NO

SÍ

RADICAL

ANTROPOCÉNTRICA

SÍ

SÍ

MODERADA

E C O C É N T R I C A

SÍ

NO

( R A D I C A L

Y

MODERADA)
No se puede sancionar por el delito ecológico si hay afectación del medio ambiente pero no del bien individual.

Sí se puede sancionar por el delito ecológico si no hay afectación del medio ambiente, pero sí del bien individual a través de la conducta contaminante.

Concurrencia copulativa: ambos son necesarios. La ausencia de alguno de ellos impide aplicar el delito ecológico.

No se puede sancionar por el delito ecológico si no hay afectación del medio ambiente.

La puesta en peligro de los bienes individuales puede ser una circunstancia agravante. 
(3) El planteamiento ecocéntrico (y el antropocéntrico moderado en lo que respecta a la estructura del injusto que vincula al medio ambiente) también se enfrenta, cuando define su estructura del injusto, a una importante dificultad: el medio ambiente no tiene unos límites perfectamente definidos y sufre de hipersensibilidad. Es un sistema dinámico e interactivo que llega finalmente a coincidir con el planeta y se ve afectado, en mayor o menor medida, por cualquier comportamiento. Ante esta situación, para determinar la estructura del injusto hay que fijar normativamente la extensión del ecosistema analizado y el grado de afectación que se va a considerar, a efectos penales, una lesión consumada (o momento consumativo en sentido estricto).

(4) La extensión del ecosistema viene condicionada por dos factores: los elementos que integra y su tamaño.

(a) Se tendrá que determinar si el bien jurídico medio ambiente se va a construir limitado a los medios y/o manifestaciones ambientales o si incorpora cuestiones culturales y territoriales.

(b) En un segundo momento se fijará, dentro del grupo de elementos recogidos por este bien, el tamaño del ecosistema tutelado.

(5) Una vez realizadas estas operaciones, se determinará qué nivel de agresión (colapso, afectación grave, simple afectación) será el momento consumativo a efectos penales (pues desde un punto de vista natural parece que siempre será el colapso o la destrucción) de la lesión del medio ambiente.

Tabla 2 
Variables en la extensión del medio ambiente (autónomo) y en la decisión normativa

sobre el momento consumativo a efectos penales

Elementos

Tamaño

$\begin{array}{lll}\text { Concepción estricta (abiótico) } & \text { Amplio } & \text { (1) Colapso } \\ \text { C. intermedia (biótico }+ \text { abiótico) } & \text { Reducido } & \text { (2) Alteración grave del equilibrio } \\ \text { C. amplia (biótico }+ \text { abiótico } & + & \text { (3) Simple alteración }\end{array}$

aspectos culturales)

Fuente: elaboración propia

(6) Ello genera una escala de probabilidades de lesión del medio ambiente.

Tabla 3

Orden creciente de las probabilidades de lesión del medio ambiente (L), puesta en

peligro abstracto (PA) y concurrencia de delitos de acumulación (A)

Amplio $\quad$ Reducido
Colapso
0 (L) 1 (PA) 4 (A)
2 (L) 3 (PA) 2 (A)

$\begin{array}{lll}\text { Alteración grave equilibrio } & 1 \text { (L) } 2 \text { (PA) } 3(\mathrm{~A}) & 3 \text { (L) } 4 \text { (PA) } 1 \text { (A) } \\ \text { Simple modificación } & 4 \text { (L) } 0 \text { (PA) } 0 \text { (A) } & 4 \text { (L) } 0 \text { (PA) } 0 \text { (A) }\end{array}$

Fuente: elaboración propia

Los números muestran en qué grado es probable, en función de las combinaciones del tamaño del ecosistema y del momento consumativo, que la agresión contra el medio ambiente pueda ser catalogada penalmente dentro de cada nivel de afectación señalado (L, PA, A). Así, la "lesión” (L), a modo de ejemplo, tendrá el siguiente orden: simple 
modificación - ecosistema reducido/amplio: producción segura (4); alteración grave ecosistema reducido: muy probable (3); colapso - ecosistema reducido: probable (2); alteración grave - ecosistema amplio: poco probable (1); colapso - ecosistema amplio: no acontece (0). Por otro lado, la tabla también compara los ítems entre sí. Dos ejemplos: resulta que, en la combinación colapso - ecosistema amplio, la lesión (L) no acontece, el peligro abstracto (PA) ${ }^{120}$ es poco probable y el delito de acumulación (A) es de concurrencia segura. Sin embargo, cuando unimos colapso y ecosistema reducido, L y A aparecen como probables y PA como muy probable. Por consiguiente, en el primer caso, toda la discusión político-criminal y dogmática se centra alrededor del delito de acumulación. En el segundo, este debate se dirige prioritariamente hacia el delito de peligro abstracto, pero no de forma única al convivir con probables situaciones lesivas y de acumulación.

En la tabla se aprecian, por tanto, las consecuencias que tiene la decisión combinada de ir reduciendo el tamaño del ecosistema y simplificando el momento consumativo a efectos penales.

(a) Se incrementa el número de conductas lesivas: disminuye el número de tipos que pueden calificarse de peligro.

(b) Se reduce el ámbito de insignificancia: aumenta el número de conductas que tienen capacidad lesiva directa suficiente.

(c) Genera una lógica disminución de los comportamientos que se incluirían en la problemática de los delitos acumulativos.

(7) Una vez que se conoce la estructura del injusto, ya sí se puede analizar, con la indicación previa de la construcción defendida, si se solicita, lege ferenda, que la tutela del medio ambiente se realice mediante delitos de lesión o de peligro. O si se interpreta,

120 Definida como la sanción de conductas que tienen capacidad lesiva directa, y que, por tanto, no incluye los delitos de acumulación. 
de lege lata, que los tipos existentes son de lesión o de peligro. Es evidente que la mención expresa a la capacidad ("puedan perjudicar gravemente el equilibrio de los sistemas naturales”) del artículo 325 CP parece que insiste en el peligro, pero, ¿este tipo no llegaría a abarcar supuestos de puesta en peligro concreto o de lesión cuando se maneje un ecosistema reducido, incluso cuando el momento consumativo fuera el colapso?

(8) Finalmente, es importante recordar que esta toma de postura en la estructura del injusto se plantea, obviamente, como la cúspide de un sistema sancionador, en cuyo primer eslabón se encuentra el derecho administrativo.

El derecho penal, el segundo y último nivel, presenta un plus en su ilícito respecto al administrativo. Ello se aprecia de forma clara cuando la relación entre el ilícito administrativo y el penal se encuentra en una escala de injusto: peligro abstracto-peligro concreto, peligro abstracto/concreto - lesión. Sin embargo, cuando en ambos ilícitos hay una referencia al mismo nivel de ofensividad, se requiere la inclusión de una cláusula de notoriedad en el tipo penal: que tenga capacidad lesiva para producir un resultado (más) grave, produzca un resultado lesivo (más) grave que el descrito administrativamente.

Lógicamente, la necesidad de introducir cláusulas de notoriedad será mayor cuanto más reducido sea el tamaño del ecosistema y más simple sea el momento consumativo, ya que se produce con más frecuencia, al aumentar el número de conductas consumadas, la coincidencia en el nivel de ofensividad descrita en el párrafo anterior.

\section{BIBLIOGRAFÍA}

ALASTUEY DOBÓN, C. El delito de contaminación ambiental, Granada, 2004.

ALENZA GARCÍA, J. F. "Las sanciones administrativas y penales en materia ambiental: Funciones y problemas de articulación”, en Corcoy Bidasolo (dir.): Derecho penal de la empresa, Pamplona, 2002, pp. 595 y ss. 
ALMELA VICH, C., "El medio ambiente y su protección penal”, en Actualidad Penal, vol. I, n. ${ }^{\text {o } 2,1998, ~ p p . ~} 25$ y ss.

ALCÁCER GUIRAO, R., "La protección del futuro y los daños cumulativos", en Revista Electrónica de Ciencia Penal y Criminología [en línea], n. ${ }^{\circ}$ 04-08, 2002, pp. 1 y ss. Recuperado el 15 de junio de 2010 de http://criminet.ugr.es/recpc/recpc 04-08.pdf.

BARREIRO, A. J., "El bien jurídico protegido en los delitos contra el medio ambiente en el CP de 1995”, en Barreiro (dir.): Estudios sobre la protección penal del medio ambiente en el ordenamiento jurídico español, 2005, pp. 1 y ss.

BLANCO LOZANO, C., El delito ecológico. Manual operativo, Madrid, 1997.

— La protección del medio ambiente en el derecho penal español y comparado, Granada, 1997.

BLOY, R., "Umweltstrafrecht: Geschichte - Dogmatik - Zukunftsperspektiven", en JuS, 1997, pp. 577 y ss.

BRANDÁRIZ GARCÍA, J. A., "Cuestiones derivadas de la concurrencia del derecho penal y del derecho administrativo en materia de tutela del medio ambiente", en Anuario da Facultade de Dereito da Universidade da Coruña, n. ${ }^{\circ}$ 7, 2003, pp. 155 y ss.

BUSTOS RAMÍREZ, J., "Necesidad de la pena, función simbólica y bien jurídico medio ambiente", en Pena y Estado, 1991, pp. 101 y ss.

CARMONA SALGADO, C., "Delitos contra los recursos naturales, el medio ambiente, la flora, la fauna y los animales domésticos. Disposiciones comunes", en Cobo del Rosal (coord.): Derecho Penal Español. Parte Especial, 2. edición, 2005, pp. 695 y ss.

CARRASCO ANDRINO, M. M., "El daño a los elementos de un espacio natural protegido: un nuevo ilícito penal”, en Morales Prats, F.; Quintero Olivares, G. (coord.): El nuevo derecho penal español: estudios penales en memoria del profesor José Manuel Valle Muñiz, Elcano, 2001, pp. 1059 y ss.

CONDE-PUMPIDO TOURON, C., "La tutela del medio ambiente. Análisis de sus novedades más relevantes", en La Ley, D-133, 1996, pp. 1550 y ss.

CORCOY BIDASOLO, M., "Los delitos relativos a la ordenación del territorio y el medio ambiente: una perspectiva criminológica”, en Corcoy Bidasolo / Ruidiaz García 
(coordinadoras): Problemas criminológicos en las sociedades complejas, 2000, Pamplona, pp. 55 y ss.

— "Protección penal del medio ambiente: legitimidad y alcance. Competencia penal y administrativa en materia de medio ambiente", en Corcoy Bidasolo (dir.): Derecho penal de la empresa, 2002, Pamplona, pp. 613 y ss.

CRAMER, P., HEINE, G., Strafgesetzbuch. Kommentar (Schönke/Schröeder), 27. ${ }^{\text {a }}$ edición, Múnich, 2006.

DE LA CUESTA ARZAMENDI, J. L., "Delitos contra los recursos naturales y el medio ambiente: Capítulo III, Título XVI, Libro II del Nuevo Código Penal de 1995”, en Actualidad Penal, 1998, pp. 287 y ss.

DE LA CUESTA AGUADO, P. M., “Algunas consideraciones acerca de la necesidad de protección del medio ambiente como bien jurídico", en Anales de la Universidad de Cádiz, XI, 1996, pp. 269 y ss.

- Causalidad de los delitos contra el medio ambiente, 2. a edición, Valencia, 1999.

DE LA MATA BARRANCO, N., Protección Penal del Ambiente y Accesoriedad Administrativa, Barcelona, 1996.

— "Delitos contra el medio ambiente: accesoriedad administrativa", en Estudios de Derecho judicial, n. ${ }^{\text {o } 75,2005, p p . ~} 9$ y ss.

ESCAJEDO SAN EPIFANIO, L., "Manifestaciones de la crisis del estado social en el simbolismo de la protección ambiental", en IeZ: Ingurugiroa eta zuzenbidea = Ambiente y derecho, n. ${ }^{\circ}$ 5, 2007, pp. 35 y ss.

FARALDO CABANA, P., "El delito de establecimiento de depósitos o vertederos de residuos peligrosos, con especial referencia al proyecto de reforma de 13 de noviembre de 2009”, en Revista Catalana de Dret Ambiental, vol. I - núm. 1, 2010, pp. 1 y ss. Recuperado el 15 de noviembre de 2010 de http://rcda.cedat.cat/index.php/rcda/article/ viewFile/7/75.

FRISCH, W., Verwaltungsakzessorietät und Tatbestandsverständnis im Umweltstrafrecht, Heidelberg, 1993. 
FUENTES OSORIO, J. L., "Formas de anticipación de la tutela penal", en Revista Electrónica de Ciencia Penal y Criminología, 8-8, 2006, pp. 1 y ss. Recuperado el 15 de junio de 2010 de http://criminet.ugr.es/recpc/08/recpc08-08.pdf.

GARCÍA ARÁN, M., "Remisiones normativas, leyes penales en blanco y estructura de la norma penal", en Estudios penales y criminológicos, n. ${ }^{\circ} 16,1992-1993$, pp. 63 y ss.

GARCÍA RIVAS, N., Delito ecológico. Estructura y aplicación judicial, Barcelona, 1998.

GIANNINI, M. S., “Ambiente: saggio sui diversi suoi aspetti giuridici”, en Rivista Trimestrale di Diritto Pubblico, 1973, pp. 15 y ss.

GIL CALVO, E., El miedo es el mensaje, Madrid, 2003.

GONZÁLEZ GUITIÁN, L., "Sobre la accesoriedad del Derecho Penal en la protección del ambiente", en Estudios penales y criminológicos, n. ${ }^{\circ} 14,1989-1990$, pp. 109 y ss.

HASSEMER, W., "Kennzeichen und Krisen des modernen Strafrecht”, en ZRP, 1992, pp. 379 y ss.

HEFENDEHL, R., “¿Debe ocuparse el Derecho penal de riesgos futuros?”, Revista Electrónica de Ciencia Penal y Criminología [en línea], n. 04-14, 2002, pp. 1 y ss. Recuperado el 15 de junio de 2010 de http://criminet.ugr.es/recpc/recpc_04-14.pdf.

— “Derecho penal medioambiental: ¿por qué o cómo?”, en Estudios públicos, n. ${ }^{\circ} 110,2008$, pp. 5 y ss.

HEINE, G., “Accesoriedad administrativa en el Derecho penal del medio ambiente”, en Anuario de Derecho penal y ciencias penales, tomo 46, 1993, pp. 289 y ss.

HOHMANN, O., "Von der Konsequenzen einer personalen Rechtsgutsbestimmung im Umweltstrafrecht", en $G A, 1992$, pp. 76 y ss.

HUERTA TOCILDO, S., "Principios básicos del Derecho penal y artículo 325 del CP”, en Revista Penal, n. ${ }^{\circ}$ 8, 2001, pp. 39 y ss.

KINDHÄUSER, U., "Elementos fundamentales del derecho penal medioambiental alemán", en Revista de Ciencias Penales, vol. 1, n. ${ }^{\circ}$ 2, 1998, pp. 497 y ss. 
KÜHL, K., “Anthropozentrische oder nichtanthropozentrische Rechtsgüter im Umweltstrafrecht?", en J. Nida-Rümelin, D. v. d. Pfordten (edit.): Ökologische Ethik und Rechtstheorie, Baden-Baden, 1995, pp. 245 y ss.

KUHLEN, L., "Der Handlungserfolg der strafbaren Gewässerverunreinigung (§ 324 StGB)", en $G A, 1986$, pp. 389 y ss.

— "Umweltstrafrecht - auf der Suche nach einer neuen Dogmatik", en ZStW, n. ${ }^{\circ}$ 105, 1993, pp. 697 y ss.

LACKNER, K.; KÜHL, K., Strafgesetzbuch, 26. a edición, Múnich, 2007.

LASCURAÍN SÁNCHEZ, J. A., "Elogio del artículo 325 del Código Penal”, en Barreiro (dir.): Estudios sobre la protección penal del medio ambiente en el ordenamiento jurídico español, Granada, 2005, pp. 265 y ss.

LÓPEZ RAMÓN, F., "El Derecho Ambiental como Derecho de la Función Pública de protección de los recursos naturales”, en Valle Muñiz (coord.): La protección jurídica del medio ambiente, Pamplona, 1997, pp. 105 y ss.

LOZANO CUTANDA, B., Derecho Ambiental Administrativo, 5. a edición, Madrid, 2004.

MARTÍNEZ BUJÁN, C., "Delitos relativos a la ordenación del territorio y la protección del patrimonio histórico y del medio ambiente", en Derecho penal. Parte especial, Valencia, 2004, pp. 727 y ss.

- Derecho penal económico y de la Empresa. Parte Especial, 2. ${ }^{\text {a edición, }}$ Valencia, 2005.

MATA Y MARTÍN, R. M., Bienes jurídicos intermedios y delitos de peligro, Granada, 1997.

— "Problemas y eficacia del Derecho penal del medio ambiente (Especial referencia a la contaminación de aguas subterráneas)", en Cuadernos de Política

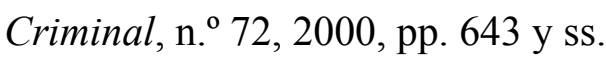

MATELLANES RODRÍGUEZ, N., Derecho penal del medio ambiente, Madrid, 2008. 
MENDO ESTRELLA, A., “Delito ‘ecológico' y norma penal en blanco: la STC de 9 de octubre, ¿una nueva orientación?”, en La ley penal: revista de derecho penal, procesal y penitenciario, n. ${ }^{\text {4 }}$ 46, 2008, pp. 103 y ss.

— El delito ecológico del art. 325.1 del Código Penal, Valencia, 2009.

MENDOZA BUERGO, B., Límites dogmáticos y político-criminales de los delitos de peligro abstracto, Granada, 2001.

- "El delito ecológico: configuración típica, estructuras y modelos de tipificación”, en Barreiro (dir.): Estudios sobre la protección penal del medio ambiente en el ordenamiento jurídico español, 2005, pp. 109 y ss.

MORALES PRATS, F., "Técnicas de tutela penal de los intereses difusos. Intereses difusos y derecho penal", en Cuadernos de Derecho Judicial, 1994, pp. 73 y ss.

— "La estructura del delito de contaminación ambiental. Dos cuestiones básicas: la ley penal en blanco y el delito de peligro", en Valle Muñiz (coord.): La protección jurídica del medio ambiente, Pamplona, 1997, pp. 225 y ss.

— "Delito de contaminación ambiental: análisis del art. 325.1. La relación entre Derecho penal y Derecho administrativo ambiental", en Quintero Olivares; Morales Prats (coord.): Estudios de Derecho ambiental: libro homenaje al profesor Josep Miquel Prats Canut, Valencia, 2008, pp. 1032 y ss.

MÜLLER-TUCKFELD, J. C., "Ensayo para la abolición del Derecho penal del medio ambiente", en La insostenible situación del Derecho penal, Granada, 2000, pp. 507 y ss.

MUÑOZ LORENTE, J., "El cambio de criterio jurisprudencial en relación con la calificación del peligro exigido para la consumación del tipo básico de los delitos contra el medio ambiente: el artículo 325 del Código Penal y su estructura de peligro hipotético (I)", en Revista interdisciplinar de gestión ambiental, n. ${ }^{\circ}$ 54, 2003, pp. 70 y SS.

— "El cambio de criterio jurisprudencial en relación con la calificación del peligro exigido para la consumación del tipo básico de los delitos contra el medio ambiente: el artículo 325 del Código Penal y su estructura de peligro hipotético (II)", en Revista interdisciplinar de gestión ambiental, n. ${ }^{\circ}$ 55, 2003, pp. 70 y ss. 
— "Diferencias y analogías entre los artículos 325 y 328 del Código Penal. El alcance del controvertido artículo 328 del Código Penal”, en Revista interdisciplinar de gestión ambiental, n. ${ }^{\circ} 49,2003$, pp. 56 y ss.

- "Juicio crítico sobre las reformas penales en materia medioambiental introducidas por la Ley Orgánica 15/2003, de 25 de noviembre, de reforma del Código Penal", en La ley penal: revista de derecho penal, procesal y penitenciario, n. ${ }^{\circ} 6,2004$, pp. 5 y ss.

OLMEDO CARDENETE, M.; RODRÍGUEZ FERNÁNDEZ, I., “Artículo 325 y 326”, en Cobo del Rosal (dir.): Comentarios al Código penal, tomo X, vol. II, Madrid, 2006, pp. 169 y ss.

OTTO, H., Grundkurs Strafrecht: die einzelnen Delikte, 7. edición, Berlín, 2005.

PALAZZO, F., "Principios fundamentales y opciones político-criminales en la tutela penal del ambiente en Italia”, en Revista Penal n. ${ }^{\circ}$, 1999, pp. 68 y ss.

PAREDES CASTAÑÓN, J. M., "La accesoriedad administrativa de la tipicidad penal como técnica legislativa: efectos políticos y efectos materiales”, en Gonzalo Quintero Olivares; Fermín Morales Prats (coord.): Estudios de Derecho ambiental: libro homenaje al profesor Josep Miquel Prats Canut, Madrid, 2008, pp. 621 y ss.

PORTILLA CONTRERAS, G., "Principio de intervención mínima y bienes jurídicos colectivos", en Cuadernos de Politica Criminal, n. ${ }^{\circ} 39$, 1989, pp. 273 y ss.

- El Derecho Penal entre el cosmopolitismo universalista y el relativismo posmodernista, Valencia, 2007.

PRATS CANUT, J.; MARQUÈS I BANQUÉ, M., "De los delitos contra los recursos naturales y el medio ambiente", en Quintero Olivares (dir.): Comentarios a la Parte Especial del Derecho penal, 5. a edición, Elcano, 2005, pp. 1157 y ss.

PRATS CANUT, J.; MARQUÈS I BANQUÉ, M.; MORÁN MORA, C., Derecho Penal Ambiental y Derecho Comunitario. La directiva IP, Elcano, 2002.

RANSIEK, A., Nomos Kommentar zum Strafgesetzbuch, Baden-Baden, 2000.

REGIS PRADO, L., "El ambiente como bien jurídico penal: aspectos conceptuales y delimitadores", en Revista Penal, n. ${ }^{\circ} 22,2008$, pp. 109 y ss. 
RENGIER, R., "Zur Bestimmung und Bedeutung der Rechtsgüter im Umweltstrafrecht”, en Neue Juristische Wochenschrift, 1990, pp. 2506 y ss.

- Strafrecht. Besonderer Teil, vol. II, 10. ${ }^{a}$ edición, Múnich, 2009.

RODRÍGUEZ MONTAÑÉS, T., Delitos de peligro, dolo e imprudencia, Madrid, 1994.

SAMSON, E., "Kausalitäts- und Zurechnungsprobleme im Umweltstrafrecht”, en ZStW, n. ${ }^{\circ} 99,1987$, pp. 617 y ss.

SANTANA VEGA, D. M., La protección penal de los bienes jurídicos colectivos, Madrid, 2000.

SANZ LÓPEZ, C.; SÁNCHEZ ALHAMA, J., Medio ambiente y sociedad. De la

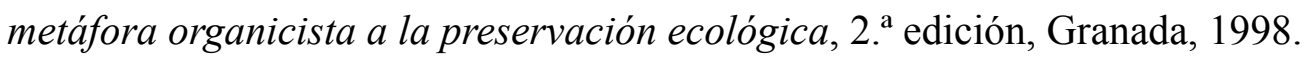

SARRABAYROUSE, E., Medio ambiente y Derecho Penal, Buenos Aires, 2008.

SEELMANN, K., "Atypische Zurechnungsstrukturen im Umweltstrafrecht", en Neue Juristische Wochenschrift, 1990, pp. 1257 y ss.

— "Risikostrafrecht", en KritV, 1992, pp. 452 y ss.

SESSANO GOENAGA, J. C., "La protección penal del medio ambiente", en Revista Electrónica de Ciencia Penal y Criminología, 04-11, 2002, pp. 1 y ss. Recuperado el 15 de junio de $2010 \mathrm{de}$ http://criminet.ugr.es/recpc/recpc_04-11.pdf.

SILVA DIAS, A., “¿Y si todos lo hiciéramos? Consideraciones acerca de la '(in) capacidad de resonancia' del Derecho penal con la figura de la acumulación”, en Anuario de Derecho penal y ciencias penales, tomo 56, 2003, pp. 433 y ss.

SILVA SÁNCHEZ, J. M., “¿Protección penal del medio ambiente? Texto y contexto del artículo 325 del Código penal”, en La Ley, D-132, 1997, pp. 1714 y ss.

— Delitos contra el medio ambiente, Valencia, 1999.

— La expansión del derecho penal, 2. a edición, Madrid, 2001.

SOTO NAVARRO, S., La protección penal de los bienes colectivos en la sociedad moderna, Granada, 2003.

— "Concreción y lesión de los bienes jurídicos colectivos", en Anuario de derecho penal y ciencias penales, tomo 58, 2005, pp. 887 y ss. 


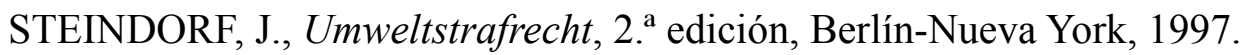

STRATENWERTH, G., “Zukunftssicherung mit den Mitteln des Strafrechts?”, en $Z S t W$, n. $^{\circ} 105,1993$, pp. 679 y ss.

TERRADILLOS BASOCO, J., "Protección penal del medio ambiente en el nuevo Código Penal español: luces y sombras”, en Estudios penales y criminológicos, n. ${ }^{\circ} 19$, 1996, pp. 289 y ss.

— "Delitos relativos a la protección del patrimonio histórico y del medio ambiente", en J. Terradillos Basoco (ed.): Derecho penal del medio ambiente, Madrid, 1997, pp. 44 y ss.

VÖHRINGER, M., “Anthropozentrische oder nichtanthropozentrische Rechtsgüter im Umweltstrafrecht", en Rechtsphilosophisches Seminar im Sommersemester 1999 zum Thema "Die Bedeutung der Philosophie für strafrechtliche Grundlagenprobleme” (Universität Tübingen - Juristische Fakultät), [en línea], 1999, pp. 1 y ss. Recuperado el 15 de junio de 2010 de http://www.jura.uni-tuebingen.de/ professoren_und_dozenten/kuehl/materialien/forschung/ustrafr.pdf.

WESSELS, J.; HETTINGER, M., Strafrecht. Besonderer Teil, vol. I, 28. ${ }^{\text {a edición, }}$ Heidelberg, 2007.

WOHLERS, W., Deliktstypen des Präventionsstrafrechts. Zur Dogmatik "moderner" Gefährdungsdelikte, Berlín, 2000. 